\title{
Two new species of Notodasus Fauchald, 1972 (Annelida: Capitellidae) from the Central Indo-Pacific region
}

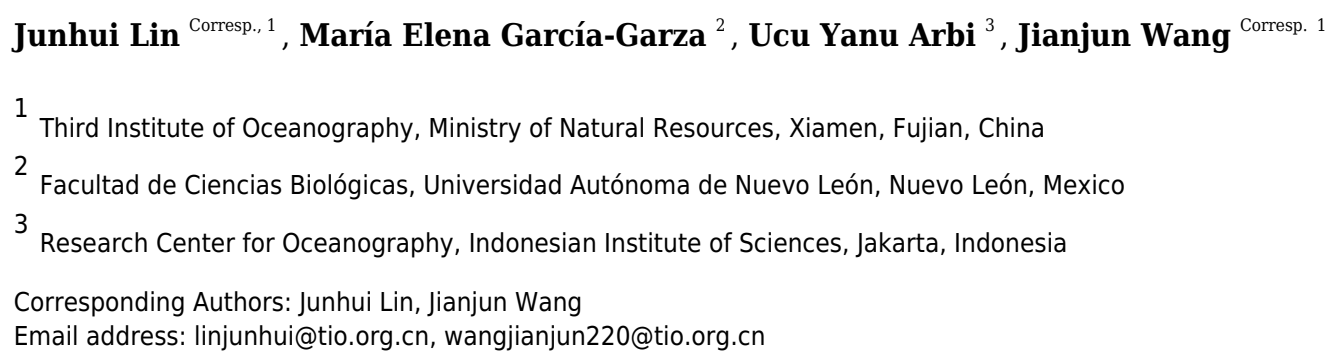

Notodasus Fauchald, 1972 is a small genus of the polychaete family Capitellidae, including ten described species worldwide. The genus is unusual in the Central Indo-Pacific, and there is no taxonomic record of Notodasus in this region. In this study, two new species of Notodasus are described and illustrated, namely Notodasus celebensis sp. nov. and Notodasus chinensis sp. nov. The former species, collected from the mixed-species seagrass beds in the Indonesian island of Sulawesi, is mainly characterized by the longitudinally striated epithelium on thoracic segments and the completely separated notopodial lobes. The latter species, obtained from coastal waters off southern China, differs from its congeners with the following characters: tessellated epithelium present on anterior thorax as well as on the dorsum of chaetigers 11 and 12, notopodial lobes fused and chaetal fascicles almost touching each other on anterior abdomen, and branchial pores evident from anterior abdomen. Comparisons are made with closely related species in this paper, and a revised key is provided to all described Notodasus species. The descriptions of the two new species represent the first record of Notodasus in this region and expand the geographical distribution of the genus. 


\section{Two new species of Notodasus Fauchald, 1972}

\section{2 (Annelida: Capitellidae) from the Central Indo-Pacific}

\section{3 region}

4

5 Junhui Lin ${ }^{1}$, María Elena García-Garza ${ }^{2}$, Ucu Yanu Arbi ${ }^{3}$, Jianjun Wang ${ }^{1}$

6

$7{ }^{1}$ Third Institute of Oceanography, Ministry of Natural Resources, Xiamen, Fujian, China

$8 \quad 2$ Facultad de Ciencias Biológicas, Universidad Autónoma de Nuevo León, Nuevo León, México

$9 \quad{ }^{3}$ Research Center for Oceanography, Indonesian Institute of Sciences, Jakarta, Indonesia 10

11 Corresponding Authors:

12 Junhui Lin ${ }^{1}$, linjunhui@tio.org.cn

13 Jianjun Wang1, wangjianjun220@tio.org.cn

14 178\# Daxue Road, Xiamen, Fujian Province, 361005, China

15 


\section{Abstract}

18 Notodasus Fauchald, 1972 is a small genus of the polychaete family Capitellidae, including ten 19 described species worldwide. The genus is unusual in the Central Indo-Pacific, and there is no taxonomic record of Notodasus in this region. In this study, two new species of Notodasus are described and illustrated, namely Notodasus celebensis sp. nov. and Notodasus chinensis sp. nov. The former species, collected from the mixed-species seagrass beds in the Indonesian island of

Sulawesi, is mainly characterized by the longitudinally striated epithelium on thoracic segments and the completely separated notopodial lobes. The latter species, obtained from coastal waters off southern China, differs from its congeners with the following characters: tessellated epithelium present on anterior thorax as well as on the dorsum of chaetigers 11 and 12, notopodial lobes fused and chaetal fascicles almost touching each other on anterior abdomen, and branchial pores evident from anterior abdomen. Comparisons are made with closely related species in this paper, and a revised key is provided to all described Notodasus species. The descriptions of the two new species represent the first record of Notodasus in this region and expand the geographical distribution of the genus.

2

\section{Introduction}

4 Polychaetes, known as an ecologically important taxon of benthic macrofauna, are frequently 5 found and numerically dominated in marine surveys. They exhibit high taxonomic diversity with over 11,000 valid species worldwide (Pamungkas et al., 2019). Of all known polychaete families,

7 Capitellidae Grube, 1862 is a family with approximately 200 described species, represented by 43 genera (García-Garza, de León-González \& Tovar-Hernández, 2019; Magalhães \& Blake, 2017). This family is usually associated with organically enriched and disturbed sediments 0 (Magalhães \& Blake, 2017), and as such, some species can be used as environmental indicators 1 (Pearson \& Rosenberg, 1978; Reish, 1980; Warren, 1991). Although extensive taxonomic 2 studies on capitellid polychaetes have been carried out, correct identification of capitellid species 3 is fairly challenging due to their simple morphology and the change in chaetal arrangement 4 during ontogeny (Blake, 2000; Hutchings, 2000). With the advancements in high-resolution 5 microscopes and molecular techniques, the taxonomy of capitellid polychaetes has been 6 extensively improved, and additional 44 new species have been added to the family since 2000, 47 based on statistics from WoRMS (Read \& Fauchald, 2018). 
48 The taxonomic study varies in different capitellid genera, and until now, the study of several 49 genera is scarce and confined to limited localities. For example, the majority of Notodasus

50

51

52

53

54

55

56

57

58

59

60

61

62

63

64

65

66

67

68

69

70

71

72

73

74

75

76

77

78 species (six out of ten species) were described from the North American coasts. Notodasus was initially established by Fauchald (1972) for the type species Notodasus magnus from the Gulf of California, mainly characterized by the presence of only capillaries on all 11 thoracic chaetigers as well as on first two abdominal chaetigers. Recently, García-Garza et al. (2009) reviewed the genus by re-examining type materials from different museums and described four additional species. In this review, the authors also proposed more diagnostic characters to differentiate species within the genus, including the epithelial texture of thorax, the degree of fusion of notopodial lobes on anterior abdomen, the shape of hooded hooks, size of abdominal lateral organs, and the methyl green staining pattern (Magalhães \& Blake, 2017). Notodasus closely resembles Dodecaseta, the latter genus erected by McCammon \& Stull (1978) and its generic definition expanded by Green (2002). These two genera overlap in generic diagnosis, and the minor morphological differences are that the former has the first two abdominal chaetigers with only capillaries while the latter bears the first one or two abdominal chaetigers with only capillaries. Recently, García-Garza et al. (2017) regarded Dodecaseta as a junior synonym of Notodasus, due to the high morphological similarity between these two genera. To date, 10 valid species are known in the genus (Fig. 1), and they are described from several localities: 6 species recorded from the North American coasts, namely N. dexterae Fauchald, 1973, N. harrisae García-Garza et al., 2009, N. hartmanae García-Garza et al., 2009, N. magnus Fauchald, 1972, N. oraria (McCammon \& Stull, 1978), and N. salazari García-Garza et al., 2009; 2 species found in the Andaman Sea, Thailand, namely N. eibyejacobseni (Green, 2002) and N. fauchaldi (Green, 2002); N. arenicola Hartmann-Schröder, 1992 and N. dasybranchoides Magalhães \& BaileyBrock, 2012 described from Ascension Island in the central Atlantic Ocean and the Hawaiian Islands, respectively.

Currently, a complete knowledge on the overall species diversity within the genus and its distributional range worldwide is still lacking, since the records of Notodasus species were only limited to few localities. In the Central Indo-Pacific, Notodasus is an unusual capitellid genus, and least studied until now, as evidenced by a lack of taxonomic record of its occurrence in this region. In this study, specimens of the genus were collected from the southern coasts of China (Fig. 2A) and from mixed-species seagrass beds in the Indonesian island of Sulawesi (Fig. 2B), 
79

80

81

82

83

84

85

86

87

88

89

90

91

92

93

94

95

96

97

98

99

100

101

102

103

104

105

106

107

108

respectively, representing the report of Notodasus in Indonesian and Chinese waters for the first time. During the taxonomic study of the material, two new species are described and illustrated herein. Detailed comparisons are made with closely related species. This study serves as a new contribution to unveil the hidden diversity of the genus Notodasus in the Central Indo-Pacific. The description of the two new species also allows us to better understand the geographical distribution of the genus. A revised key to all Notodasus species is also provided in this paper.

\section{Materials \& Methods}

The Notodasus specimens were collected from the southern coasts of China (Fig. 2A) during 2017-2018 and from mix-species seagrass beds of northern Sulawesi Island, Indonesia (Fig. 2B) in May 2014, respectively (for more detail, see Table 1). Indonesian specimens examined in this study were collected with permission of the Ministry of Research and Technology of the Republic of Indonesia (permit no. 135/SIP/FRP/SM/V/2014). In Indonesia, a PVC corer (10 cm in inner diameter) was used to collect sediment samples which were later washed through a 0.5 $\mathrm{mm}$ sieve in the field. In China, the Notodasus specimens were collected by means of a grab sampler (surface area $0.05 \mathrm{~m}^{2}$ ), and then sieved through a $0.5 \mathrm{~mm}$ sieve on board. All retained specimens were fixed with 7\% diluted formalin in seawater. In the lab, Notodasus specimens were transferred to $70 \%$ ethanol.

Light microscope images were obtained by means of a Leica M205A stereomicroscope equipped with Leica DFC 550 digital camera. The structure of hooded hooks was observed under a light microscope using oil immersion (Axio Imager Z2; ZEISS, Oberkochen, Germany). A Scanning Electron Microscopy (SEM) analysis was conducted to observe the ultrastructure of abdominal hooks. In brief, the specimens were placed in an ultrasonic chamber with distilled water for 60 seconds to remove the hoods of the abdominal hooks. The treated specimens were dehydrated and then dried in a drying oven at $60^{\circ} \mathrm{C}$ for 5 minutes. Finally, specimens were mounted on a stub and coated with gold. SEM observations were performed using ZEISS SUPRA 55 SAPPHIRE at Xiamen University, China. The methyl green staining pattern (MGSP) was used to identify the distribution of glandular areas, following the protocol of Warren et al. (1994). Morphological terminology and the characters used for classification follow those of Warren et al. (1994). 
109 Type material of several Notodasus species were reviewed from the Natural History Museum 110 of Los Angeles County -Allan Hancock Foundation (LACM-AHF) and the Colección

111 Poliquetologica de la Universidad Autonoma de Nuevo León (UANL). The type material of the

112 two new species described herein are deposited in the Third Institute of Oceanography, Ministry

113 of Natural Resources, Xiamen, China.

114

115

Nomenclatural acts

116 The electronic version of this article in Portable Document Format (PDF) will represent a

117 published work according to the International Commission on Zoological Nomenclature (ICZN),

118 and hence the new names contained in the electronic version are effectively published under that

119 Code from the electronic edition alone. This published work and the nomenclatural acts it

120 contains have been registered in ZooBank, the online registration system for the ICZN. The

121 ZooBank LSIDs (Life Science Identifiers) can be resolved and the associated information viewed

122 through any standard web browser by appending the LSID to the prefix http://zoobank.org/. The

123 LSID for this publication is: urn:lsid:zoobank.org:pub:6342781B-D33C-4FF8-85BD-

124 37D185FC2403. The online version of this work is archived and available from the following

125 digital repositories: PeerJ, PubMed Central and CLOCKSS.

126

127 Results

128 Systematic account

129 Class Polychaeta Grube, 1850

130 Family Capitellidae Grube, 1862

131 Genus Notodasus Fauchald, 1972

132 Notodasus Fauchald, 1972: 246-247, P1.51 fig a-c; Fauchald, 1977: 34; García-Garza,

133 Hernández-Valdez \& de León-González, 2009: 810; García-Garza \& de León-González, 2011:

134 35; Magalhães \& Bailey-Brock, 2012: 28; García-Garza, de León-González \& Harris, 2017: 94,

135 fig. 1; Magalhães \& Blake, 2017.

136 Dodecaseta McCammon \& Stull, 1978: 40-43, figs 1-3; Green, 2002: 311.

137 Type species. Notodasus magnus Fauchald, 1972

138

139 Notodasus celebensis sp. nov. Lin, García-Garza \& Arbi

Peer) reviewing PDF | (2019:04:36363:1:1:NEW 31 Jul 2019) 
140 urn:lsid:zoobank.org:act:A8E8DAA2-650A-4F10-AD10-3799C447670B

141 Figs. $3 \mathrm{~A}-\mathrm{G}, 4 \mathrm{~A}-\mathrm{G}, 5 \mathrm{G}-\mathrm{H}$

142 Etymology. The specific name is derived from the type locality, Sulawesi Island. Celebes is the 143 historical name for modern Sulawesi.

144 Holotype. TIO-BTS-Poly-101 (sta. SGT3-3), Tanjung Merah Village, the east coast of North 145 Sulawesi (Fig. 2), Indonesia, [ $\left.1^{\circ} 23^{\prime} 41^{\prime \prime} \mathrm{N}, 125^{\circ} 06^{\prime} 43^{\prime \prime} \mathrm{E}\right], 1 \mathrm{~m}$ depth, fine sand, incomplete, coll. 146 Junhui Lin, May 2014.

147 Paratype. TIO-BTS-Poly-102 (sta. SGT1-2), one specimen, Kema Village, the east coast of 148 North Sulawesi, Indonesia, [1 $\left.{ }^{\circ} 23^{\prime} 11^{\prime \prime} \mathrm{N}, 125^{\circ} 06^{\prime} 08^{\prime \prime} \mathrm{E}\right], 1 \mathrm{~m}$ depth, fine sand, incomplete, coll. 149 Junhui Lin, May 2014; TIO-BTS-Poly-103, one specimen, same information as TIO-BTS-Poly150102.

151 Comparative material examined. N. magnus holotype (LACM-AHF POLY 031), SW Punta

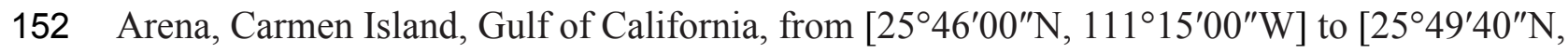
$153111^{\circ} 15^{\prime} 30^{\prime \prime} \mathrm{W}$ ], 29-35 m, 18 March 1949; N. fauchaldi paratype (LACM-AHF POLY 2100) st. 154 E-20 m/BC, Andaman Sea, Thailand, [8³0'N, 98¹2'E], 21 m, 22 April 1996, muddy sand, coll. 155 SB, ChA; N. harrisae holotype (UANL-6510), Baja California Sur, La Paz Bay, El Tesoro

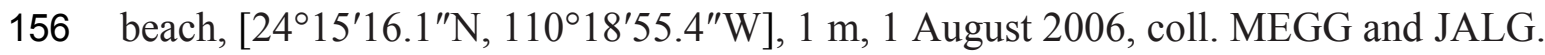

157 Distribution. Currently known from the Sulawesi Island, Indonesia.

158 Diagnosis. Prostomium rounded, with digitate palpode. Thorax having one achaetous 159 peristomium and 11 chaetigers with bilimbate capillary chaetae only. First chaetiger biramous. 160 First two abdominal chaetigers with only capillary chaetae in both rami, thereafter, with hooded 161 hooks only. Longitudinally striated epithelium through chaetiger 8. Notopodial lobes completely 162 free along abdomen. Multidentate hooded hooks with four rows of small teeth above main fang. 163 Lateral organs present on thorax and abdomen.

164 165 166 167 168 169 170

\section{Description}

All specimens incomplete. Holotype anterior fragment with 40 chaetigers, $41.0 \mathrm{~mm}$ long, 2.8 $\mathrm{mm}$ wide in abdomen. Paratypes ranging from $20 \mathrm{~mm}$ long by $2.2 \mathrm{~mm}$ wide (35 chaetigers) to $25.5 \mathrm{~mm}$ long by $2.5 \mathrm{~mm}$ wide (39 chaetigers). Body slightly coiled. Color in alcohol yellowish white (Fig. 3A). The dorsal epithelium of anterior abdomen slightly damaged. Prostomium rounded, with digitate palpode (Fig. 3B, C). Everted proboscis papillated in paratype (TIO-BTSPoly-103). Eyespots not observed. Peristomium achaetous, wider than long, same length as first 
171 chaetiger, but narrower. Peristomium and first six chaetigers with epithelium longitudinally

172 striated (Figs. 3B-D, 4A-B, 5G), chaetigers 7-8 slightly striated, following segments smooth.

173 Thorax with 11 chaetigers, exclusively with bilimbate capillary chaetae in both rami (Fig. 4A).

174 First chaetiger biramous. All thoracic chaetigers biannulated, 1.5-2 times as wide as long, with

175 deep inter-segmental and clear intra-segmental grooves (Figs. 3B, 4A-B). Chaetal fascicles

176 inserted just posterior to midline of thoracic segments (Fig. 3B, D). Notopodia dorsolateral in

177 anterior thorax, moving dorsally to end of thorax, and neuropodia lateral. Lateral organs present

178 along body, located between noto- and neuropodia; those in thorax closer to notopodia, as small

179 rounded pores; abdominal ones closer to superior neuropodial lobes, as small protuberances (Fig.

180 3G). Genital pores not observed.

181 Transition between thorax and abdomen marked by constriction and reduced length of

182 abdominal segments (Figs. 3E-F, 4C-D, 5H). First two abdominal segments biannulated, with

183 bilimbate capillary chaetae only and partially developed neuropodial lobes; subsequent

184 abdominal segments with hooded hooks and expanded neuropodial lobes (Figs. 3E-F, 4D-E,

$1855 \mathrm{H}$ ). Notopodial lobes free along abdomen (Figs. 3F, 4C, 5H), approaching each other on

186 anterior abdomen, but becoming further separated posteriorly. Notopodia with approximately 40

187 hooded hooks per fascicle. Abdominal neuropodial lobes separated mid-ventrally, extending

188 from ventral area to the dorsolateral region (Figs. 3E, 4C). Neuropodial lobes covered with

189 hooded hooks, leaving enlarged superior neuropodial lobe (Fig. 4D, F). Chaetal fascicles in

190 neuropodia with more than 200 hooded hooks. Notopodial and neuropodial abdominal hooded

191 hooks similar along body, with long anterior shaft, angled node, distinct constriction, developed

192 shoulder, and short hood; posterior shaft curved, longer than anterior one, attenuated to terminal

193 end (Fig. 4G). Hooded hooks with four rows of small teeth above main fang (Fig. 4G). Main

194 fang subtriangular, longer than wide.

195 Branchiae not known, as all examined specimens incomplete. Pygidium not known.

196 Variations. The holotype is a larger individual than paratypes. Meanwhile, the longitudinally

197 striated epithelium is more evident in the holotype.

198 Methyl green staining (Figs. 4A-D, 5G-H). Thorax uniformly stained light green except by the

199 presence of a medium green transverse band on peristomium. Methyl green stain on first two

200 abdominal chaetigers slightly darker than on thorax. Abdominal chaetigers 3-13 with medium

201 green stain on dorsolateral areas between noto- and neuropodial lobes and ventral areas around

Peer] reviewing PDF | (2019:04:36363:1:1:NEW 31 Jul 2019) 
202 neuropodia, a longitudinal mid-ventral band stained with medium green, and light green stain on 203 parapodial tori and lateral organs. Abdominal chaetiger 14 and following ones stained with a 204 light green completely, and mid-ventral band faded.

205

206 Notodasus chinensis sp. nov. Lin, García-Garza \& Wang

207 urn:lsid:zoobank.org:act:201C23E8-5FD1-4D12-813D-B0A649A0DC11

208 Figs. 6A-F, 7A-D, 8A-F, 9A-B

209

210

Etymology. The specific name is derived from the type locality, Chinese waters.

211 Holotype. TIO-BTS-Poly-105 (sta. GFC-S31), one specimen, Qinzhou Bay, Guangxi Province,

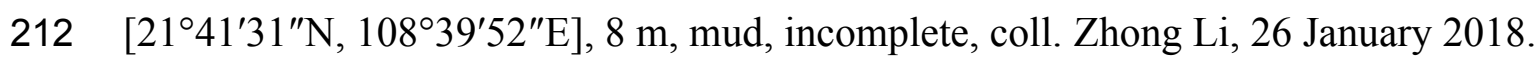

213 Paratype. 11 specimens: TIO-BTS-Poly-106 (sta. GFC-S31), 4 incomplete specimens, same 214 information as holotype, one mounted on SEM stub; TIO-BTS-Poly-107 (sta. GFC-S33), one

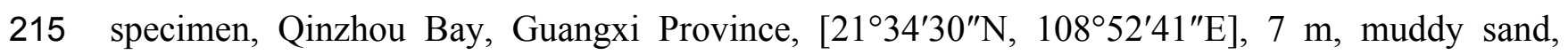
216 incomplete, coll. Zhong Li, 26 January 2018; TIO-BTS-Poly-108 (sta. GFC-S11), one specimen,

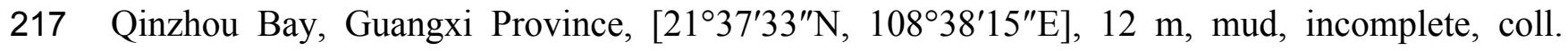
218 Zhong Li, 27 October 2017; TIO-BTS-Poly-109 (sta. GFC-S24), one specimen, Qinzhou Bay,

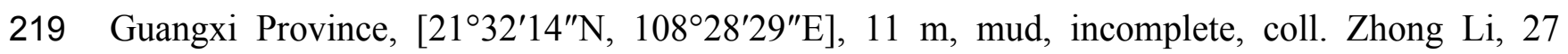
220 October 2017; TIO-BTS-Poly-112 (sta. GFC-S17), 2 specimens, Qinzhou Bay, Guangxi

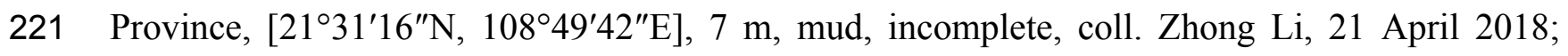
222 TIO-BTS-Poly-113 (sta. GFC-S18), one specimen, Qinzhou Bay, Guangxi Province, 223 [21 $\left.35^{\prime} 39^{\prime \prime} \mathrm{N}, 108^{\circ} 34^{\prime} 41^{\prime \prime E}\right], 9$ m, muddy sand, incomplete, coll. Zhong Li, 22 April 2018.

224 Additional material examined. TIO-BTS-Poly-110, 2 specimens, Daya Bay, Guangdong 225 Province, [22 $36^{\prime} 43^{\prime \prime} \mathrm{N}, 114^{\circ} 43^{\prime} 12^{\prime \prime} \mathrm{E}$ ], 9 m, mud, incomplete, coll. Junhui Lin, 30 August 2017, 226 one mounted on SEM stub.

227 Comparative material examined. $N$. oraria holotype (LACM-AHF POLY 1248), Palos Verdes 228 Peninsula, California, USA, 30-180 m; $N$. dexterae holotype (LACM-AHF POLY 2190), Naos 229 Island, Panama, [8 ${ }^{\circ} 53^{\prime} \mathrm{N}, 79^{\circ} 33^{\prime} \mathrm{W}$ ], intertidal, sand, incomplete, July 1969.

230 Distribution. Currently known from shallow subtidal waters of the Qinzhou Bay (Guangxi 231 Province) and Daya Bay (Guangdong Province), the southern coast of China.

232 Diagnosis. Prostomium conical, with short palpode. Thorax having one achaetous peristomium 
233 and 11 chaetigers with bilimbate capillary chaetae only. First chaetiger biramous. First 234 abdominal chaetigers with only capillary chaetae in both rami, thereafter, with hooded hooks 235 only. Tessellated epithelium through chaetiger 5 as well as on dorsum of chaetigers 11 and 12. 236 Notopodial lobes fused dorsally into a raised coalesced lobe on abdominal chaetigers $2-4$, while 237 fused but not raised on abdominal chaetigers 5-11. Multidentate hooded hooks with four rows of 238 small teeth above main fang. Lateral organs present on thorax and abdomen. Branchiae present, 239 retractile, arising just above neuropodial hooks. Branchial pores commencing from anterior 240 abdomen.

241

\section{Description}

243 All specimens incomplete. Holotype anterior fragment with 67 chaetigers, $21.6 \mathrm{~mm}$ long, 1.7 $244 \mathrm{~mm}$ wide in abdomen (maximum width $1.9 \mathrm{~mm}$ at chaetiger 4). Paratypes ranging from $7.7 \mathrm{~mm}$ 245 long by $0.6 \mathrm{~mm}$ wide in abdomen (23 chaetigers; maximum width $1.0 \mathrm{~mm}$ at chaetiger 4 ) to 87.4 $246 \mathrm{~mm}$ long by $2.8 \mathrm{~mm}$ wide in abdomen (broken into two parts; more than 100 chaetigers; 247 maximum width $3.7 \mathrm{~mm}$ at chaetiger 4). Body slightly coiled. Color in alcohol whitish tan (Fig. 248 6A). Prostomium conical, with short palpode. Everted proboscis distally ciliated, and proximal 249 portion with numerous minute papillae (Figs. 6A-B, 8A-B). Peristomium about same length as 250 first chaetiger, but narrower. Eyespots present, covered by lateral margin of peristomium (TIO251 BTS-Poly-106). Peristomium and first five chaetigers with epithelium tessellated, dorsum of 252 chaetigers 11 and 12 slightly tessellated, and remaining segments smooth (Figs. 6A-B, 8A-B).

253 Thorax with 11 chaetigers, exclusively with bilimbate capillary chaetae in both rami (Figs. 6A, 254 7A-C, 8A). First chaetiger biramous. Thoracic chaetigers biannulated, being of similar length, 255 3.5-5 times as wide as long, with clear inter-segmental and intra-segmental grooves (Figs. 6A-D, 256 8A-B). Notopodia dorsolateral in first chaetiger, approaching each other gradually to end of 257 thorax, and neuropodia lateral (Fig. 8A). Chaetal fascicles inserted just posterior to midline of 258 thoracic segments (Figs. 6A-C, 7A-B, 8A-B). Lateral organs evident from posterior thorax, 259 located between noto- and neuropodia; those in posterior thorax closer to notopodia, as small 260 rounded pores (Fig. 6D); those in the abdomen closer to superior neuropodial lobes from 261 chaetiger 12 (first abdominal chaetiger), as small protuberances, protruded above surface in 262 posterior segments (Figs. 6F, 7B, 8E). Genital pores not seen.

263 Transition between thorax and abdomen marked by constriction and reduced length of first 
264 abdominal segment (Figs. 6C-E, 7B, 8A). First abdominal segments biannulated, with bilimbate 265 capillary chaetae in both rami and partially developed neuropodial lobes; subsequent abdominal 266 segments with hooded hooks and expanded neuropodial lobes (Figs. 6C-E, 8A). Notopodial 267 lobes fused dorsally into a raised coalesced lobe on abdominal chaetigers 2-4 (Figs. 6C, 8C), 268 while fused but not raised on abdominal chaetigers 5-11. Notopodial fascicles almost touching 269 each other on abdominal chaetigers 2-11, forming a continuous line (Fig. 8A, C). From 270 abdominal chaetiger 11, gap between notopodial lobes becoming gradually larger. Neuropodial 271 lobes expanded, separated mid-ventrally (Fig. 8D), extending from ventral area to dorsolateral 272 region (Fig. 6D, E). Neuropodial lobes covered with hooks, leaving enlarged superior 273 neuropodial lobe (Fig. 6D). Notopodial fascicles positioned posterior part of segment (Fig. 8A, 274 C). Chaetal fascicles with approximately 30 hooks in notopodia and more than 150 hooks in 275 neuropodia. Notopodial and neuropodial abdominal hooded hooks similar along body, with long 276 anterior shaft, developed shoulder, bulbous node, indistinct constriction, and short hood; 277 posterior shaft slightly longer than anterior shaft (Fig. 8F). Four rows of small teeth above main 278 fang (Figs. 7D, 8F). Main fang subtriangular, longer than wide.

279 Branchiae digitiform in holotype, may be retractile, only observed on some superior 280 neuropodial lobes of abdominal segments (Fig. 6F), arising from a small pore just above 281 neuropodial fascicles. Pygidium not seen.

282 Variations. All specimens are incomplete, without posterior abdomen. Tessellated epithelium on 283 chaetigers 11 and 12 are more evident in larger specimens. Fused notopodial lobes located on a 284 raised coalesced lobe on abdominal chaetigers 2-4 in larger specimens, while on abdominal 285 chaetigers $2-3$ in smaller specimens.

286 Methyl green staining pattern (Figs. 8A-C, 9A-B). Thorax and abdominal segments 287 completely stained light green except that dark green stain from chaetiger 6 to prechaetal area of 288 chaetiger 7 , and moderate green stain from chaetiger 11 to prechaetal area of chaetiger 12.

\section{Discussion}

291 On Notodasus celebensis sp. nov.

292 Among all ten known Notodasus species worldwide, Notodasus celebensis sp. nov. (Fig. 5G) is 293 most similar to N. magnus (Fig. 5A) and N. harrisae (Fig. 5C) from the Gulf of California, and $N$. 294 fauchaldi (Fig. 5E) from the Andaman Sea by having longitudinally striated epithelium on 
295 thoracic segments, whereas the rest members of the genus bear thoracic segments with 296 tessellated epithelium. However, N. celebensis sp. nov. differs from these three closely related 297 species, based on other morphological characters (Table 2). N. celebensis sp. nov. is 298 distinguished from $N$. magnus in that: (1) N. celebensis sp. nov. bears rounded prostomium with 299 digitate palpode compared with conical prostomium with short palpode in N. magnus; (2) striated 300 epithelium is present on more thoracic segments in N. magnus than in N. celebensis sp. nov.; (3) 301 abdominal notopodial lobes are completely separated along the abdomen in $N$. celebensis sp. 302 nov., while in N. magnus, they are fused with a median constriction in anterior abdomen; (4) $N$. 303 celebensis sp. nov. has abdominal hooks with four rows of small teeth above main fang instead 304 of three rows as in N. magnus. N. celebensis sp. nov. also differs from N. harrisae in that: (1) N. 305 celebensis sp. nov. bears prostomium with digitate palpode and without eyespots compared with 306 prostomium with short palpode and eyespots in $N$. harrisae; (2) striated epithelium are present 307 on anterior 8 chaetigers of $N$. celebensis sp. nov. but on the entire thorax of $N$. harrisae; (3) 308 abdominal notopodial lobes are completely separated along the abdomen in $N$. celebensis sp. nov. 309 whereas they are fused in the anterior abdomen of $N$. harrisae; (4) abdominal hooks of $N$. 310 celebensis sp. nov. have four rows of small teeth above main fang instead of three rows as in $N$. 311 harrisae. Furthermore, N. celebensis sp. nov. differs from N. fauchaldi in that: (1) N. celebensis $312 \mathrm{sp}$. nov. bears prostomium with digitate palpode and without eyespots compared with 313 prostomium with short palpode and eyespots in $N$. fauchaldi; (2) abdominal notopodial lobes are 314 completely separated along the abdomen in N. celebensis sp. nov. whereas they are fused in the 315 anterior abdomen of N. fauchaldi; (3) in anterior abdomen, lateral organs are situated in a pit in 316 N. celebensis sp. nov. but protruded above surface in N. fauchaldi.

317 The inhabiting environment is also different: $N$. celebensis sp. nov. was found in the shallow 318 nearshore seagrass beds characterized by fine sand; N. magnus was collected from soft sediments 319 mixed with sand, mud, and pebbles at depths of 29 to $35 \mathrm{~m} ; N$. harrisae was found to inhabit 320 intertidal and shallow fine sand; and $N$. fauchaldi was recorded in a variety of sediments at 321 depths of 21 to $55 \mathrm{~m}$.

322 As for methyl green staining, the most relevant characteristic of Notodasus celebensis is that it 323 has a dark transverse band on peristomium and medium green stain on dorsolateral areas of 324 abdominal chaetigers 3-13 (Fig. 5G-H), which is distinct from the other three Notodasus species. 325 Based on the original descriptions of type species, N. magnus has darker prechaetal and 
326 postchaetal transverse band on abdominal chaetigers 3-5 (Fig. 5B); N. harrisae has two dark 327 dorsolateral longitudinal bands on abdominal chaetigers 3-22 (Fig. 5D); and N. fauchaldi has 328 dark green stain on dorsum of abdominal chaetigers except for notopodial lobes and lateral 329 organs (Fig. 5F). Moreover, the latter three species have uniform light green stain on anterior 330 thorax, without a dark band on peristomium.

331 Quite a few monographs and papers dealing with Indonesian polychaetes have been published 332 (Caullery, 1915, 1944; Horst, 1903, 1910, 1912, 1015, 1916a, 1916b, 1917, 1924; Pettibone, 333 1970, 1971; AI-Hakim \& Glasby, 2004; Pamungkas, 2015, 2017). In these publications, seven 334 capitellid genera were taxonomically recorded in Indonesian waters, namely Capitella, 335 Dasybranchus, Mediomastus, Notomastus, Polymastigos, Promastobranchus, and Scyphoproctus. 336 Notodasus celebensis sp. nov., which is newly described from Sulawesi Island, represents the report of Notodasus in Indonesian waters for the first time. The number of capitellid genera in this area rises to eight genera.

\section{On Notodasus chinensis sp. nov.}

341 $N$. chinensis sp. nov. mostly resembles $N$. oraria (Fig. 9C) from the waters off California, USA and N. dexterae (Fig. 9D) from the Pacific coast of Panama. These three species share the tessellated epithelium on thoracic segments, the fused notopodial lobes in anterior abdomen, and the mid-ventrally separated neuropodial lobes along abdomen. However, N. celebensis sp. nov. bears tessellated epithelium on the dorsum of chaetigers 11 and 12 and branchial pores commencing from abdominal chaetiger 2, which are not found in other species in the genus. In addition to the above morphological characters exclusive to $N$. chinensis sp. nov., $N$. chinensis $\mathrm{sp}$. nov. can be distinguished from $N$. oraria in that: (1) eyespots are present in $N$. chinensis sp. nov while absent in $N$. oraria; (2) thoracic segments have tessellated epithelium on anterior 5 chaetigers in $N$. chinensis sp. nov. while on chaetigers $1-8$ of $N$. oraria. $N$. chinensis sp. nov. also differs from $N$. dexterae in that: (1) lateral organs are situated in a pit in anterior abdomen in $N$. chinensis sp. nov. while protruded above surface in N. dexterae; (2) abdominal hooks have four rows of small teeth above main fang in N. chinensis sp. nov. instead of five rows of small teeth as in $N$. dexterae. For more details, see Table 3.

In terms of inhabiting environment, $N$. chinensis sp. nov. is described from shallow subtidal 356 mud or muddy sand (7-12 m), N. dexterae inhabits intertidal sand, and $N$. oraria is mainly found 
357 in muddy sediment at depths of $1-180 \mathrm{~m}$.

358 Furthermore, $N$. chinensis sp. nov. has a distinct methyl green staining pattern: dark green

359

360

361

362

363

364

365

366

367

368

369

370

371

372

373

374

375

376

377

378

379

380

381

382

383

384

385

386 stain on chaetigers 7-8, medium green stain on chaetigers 11-12, and light green stain on the remaining segments (Fig. 9A-B). According to the original descriptions of type materials, $N$. oraria has medium green stain from the postchaetal part of chaetiger 6 to prechaetal part of chaetiger 10, and dark green stain on chaetigers 11 and 12 (Fig. 9C); N. dexterae has medium green stain on chaetigers 9-13, and two dark dorsolateral bands from the third abdominal chaetiger (Fig. 9E).

According to "Checklist of marine biota of China seas" (Liu, 2008), a total of 17 capitellid species was recorded from Chinese waters, represented by ten genera, including Capitella, Dasybranchus, Heteromastus, Leiochrides, Mastobranchus, Neoheteromastus, Neomediomastus, Notomastus, Parheteromastus, and Rashgua. In this study, Notodasus is recorded for the first time in Chinese waters.

\section{On the generic definition of Notodasus}

The genus Notodasus was originally erected by Fauchald (1972), distinct from other capitellid genera mainly by having only capillaries on all 11 thoracic chaetigers as well as on the first two abdominal ones. Since then, eight Notodasus species had been added to the genus, all in agreement with the generic definition. The genus Dodecaseta was initially established by

McCammon \& Stull (1978), then its definition was expanded by Green (2002) as having first one or two abdominal chaetigers with capillaries instead of first abdominal chaetiger as in the original definition. Of the three known Dodecaseta species, D. eibyejacobseni completely matched the generic diagnosis of Notodasus. The remaining two species, $D$. oraria and $D$. fauchaldi, agree well with the generic definition of Notodasus except that they bear abdominal capillaries only on first abdominal chaetiger instead of on first two abdominal chaetigers as in Notodasus. García-Garza et al. (2017) believed that the above morphological difference might be due to the fact that these two Dodecaseta species were described based on immature specimens. It is well known that the replacement of hooded hooks by capillaries occurs in some capitellid genera during ontogeny (Ewing, 1982; Blake, 2000), and the number of chaetigers with capillaries will change until the adult condition is reached. Based on the high morphological 
387 similarity, García-Garza et al. (2017) considered Dodecaseta as a junior synonym of Notodasus, 388 without any technical change in the generic definition.

389 In addition to the presence of capillaries on all 11 thoracic chaetigers and first two abdominal

390

391

392

393

394

395

396

397

398

399

400

401

402

403

404

405

406

407

408

409

410

411

412

413

414

415

416

417 chaetigers, Notodasus bears other distinctive morphological characters: partially developed neuropodia and protruded lateral organs on the last one or two chaetigers with capillaries (Green, 2002). In this study, one of the newly described species, $N$. celebensis sp. nov., completely matches the generic diagnosis of Notodasus. However, the other species, N. chinensis sp. nov., agrees with the generic diagnosis of Notodasus in most morphological characters except that all examined specimens are characterized by the presence of capillaries on first abdominal chaetiger and absence on the following abdominal segments, irrespective of body size. Given that the specimens of $N$. chinensis sp. nov. were collected in different seasons (October 2017, January 2018, and April 2018), we believe that N. chinensis sp. nov. has capillaries restricted to chaetigers 1-12, including 11 thoracic chaetigers and first abdominal chaetiger. Therefore, we suggest expanding the generic definition of Notodasus to have capillaries on all 11 thoracic chaetigers as well as on first one or two abdominal chaetigers, to accommodate the new species. To better clarity the chaetal arrangement of the first two abdominal chaetigers during ontogeny, more specimens of Notodasus species at different development stages are required.

\section{Conclusions}

Located between the Pacific Ocean and the Indian Ocean, the Central Indo-Pacific region is an important marine biodiversity hotspot with especially rich marine life. In this region, Notodasus is a poorly known group, and prior to this study, there was no taxonomic report of Notodasus species. The description of new Notodasus species from Sulawesi Island and southern China indicates that there is higher diversity within the genus than expected, and this contributes to better understand its diversity worldwide. Besides, this study provides more data about the ecological aspects of Notodasus. However, future efforts should be devoted to the taxonomy of polychaete fauna in this region due to relatively scant information on this group.

Key to Notodasus species (modified from García-Garza et al., 2009)

1. Epithelium longitudinally striated on all or part of thoracic segments .2 
418 - Epithelium tessellated on all or part of thoracic segments 5

419 2. Epithelium longitudinally striated throughout the thorax N. magnus Fauchald, 1972

420 - Epithelium longitudinally striated not exceeding chaetiger 9 .3

421 3. Notopodial lobes completely free throughout the abdomen N. celebensis sp. nov.

422 - Notopodial lobes fused dorsally in anterior abdomen. . .4

4. Fascicles of notopodial hooded hooks forming a continuous line in anterior abdomen, abdominal neuropodial lobes fused ventrally, hooded hooks with three rows of teeth above main fang N. harrisae García-Garza, Hernández-Valdez \& de León-González, 2009

- Fascicles of notopodial hooded hooks clearly separated along abdomen, neuropodial lobes separated mid-ventrally along the abdomen, hooded hooks with four rows of teeth above main fang N. fauchaldi (Green, 2002)

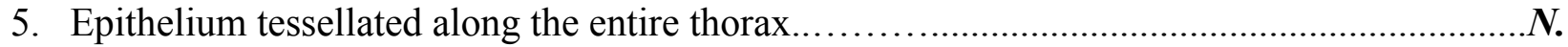
hartmanae García-Garza, Hernández-Valdez \& de León-González, 2009

- Epithelium tessellated in anterior thorax. 6

6. Notopodial lobes completely free throughout the abdomen........................... 7

- Notopodial lobes fused dorsally in anterior abdomen..........................................

7. Thoracic epithelium tessellated on segments 1-8, hooded hooks with three rows of teeth above main fang and angled node, first two abdominal chaetigers stained dark green.............. salazari García-Garza, Hernández-Valdez \& de León-González, 2009

- Thoracic epithelium tessellated on segments 1-6, hooded hooks with two rows of teeth above main fang and indistinct node, first two abdominal chaetigers stained light green or do not stain

8. Abdominal lateral organs protruded, dark green stain on chaetiger 14 and following segments except for parapodial tori. ..N. eibyejacobseni (Green, 2002)

- Abdominal lateral organs situated in deep pits, no distinct staining pattern. N. dasybranchoides Magalhães \& Bailey-Brock, 2012

9. Posterior neuropodial lobes small, fused mid-ventrally, hooded hooks with four rows of teeth above main fang and angled node. N. arenicola Hartmann-Schröder, 1992

- Neuropodial lobes separated mid-ventrally .10

10. Notopodial fascicles almost touching each other in anterior abdomen; the epithelium 
448

449

450

451

452

453

454

455

456

457

458

459

460

461

462

463

464

465

466

467

468

469

470

471

472

473

474

475

476

477

478

tessellated on the dorsum of chaetigers 11-12.

- Notopodial fascicles separated in anterior abdomen; chaetigers 11-12 smooth .11

11. Fused notopodial lobes without a median constriction, hooded hooks with five rows of teeth above main fang N. dexterae Fauchald, 1973

- Fused notopodial lobes with a median constriction, hooded hooks with four rows of teeth above main fang. N. oraria (McCammon \& Stull, 1978)

\section{Acknowledgements}

We are grateful to Mr. Heshan Lin and Mr. Zhiyuan Ma for their assistance with field sampling when in Indonesia. We thank Dr. Xikun Song from Xiamen University, China for his assistance in SEM observations, Dr. Kun Liu for the suggestion for preparing Figure 1 and 2, and Dr. Zhong Pan for editing of the manuscript. We would like to thank Leslie Harris (LACM-AHF) for her help during one of our authors (M.E. G.-G.) visit to the museum. We also thank Dr. Patricia Gandini, Dr. Wagner Magalhães, and Dr. Camila da Silva for their valuable comments and suggestions on the earlier version of the manuscript.

\section{References}

AI-Hakim Inayat, Glasby CJ. 2004. Polychaeta (Annelida) of the Natuna Islands, South China Sea. Raffles Bulletin of Zoology, Supplement 11: 25-45.

Blake JA. 2000. Family Capitellidae Grube, 1862. In: Blake JA, Hilbig B, Scott PV, eds. Taxonomic atlas of the benthic Fauna of the Santa Maria Basin and the western Santa Barbara Channel. Volumen 7. The Annelida part 4, Polychaeta: Flabelligeridae to Sternaspidae. California: Santa Barbara Museum of Natural History, 47-96.

Caullery M. 1915. Sur les Térébelliens du genere Pista Malmgr. Et en particulier sur les uncini de ces annelids. Bulletin de la Societe Zoologique de France 40: 68-78.

Caullery M. 1944. Polychètes Sédentaires de l'Expédition du Siboga: Ariciidae, Spionidae, Chaetopteridae, Chlorhaemidae, Opheliidae, Oweniidae, Sabellariidae, Sternaspidae, Amphictenidae, Ampharetidae, Terebellidae. Siboga-Expeditie Uitkomsten op Zoologisch, 
479

480

481

482

483

484

485

486

487

488

489

490

491

492

493

494

495

496

497

498

499

500

501

502

503

504

505

506

507

508

509

Bonatisch, Oceanographisch en Geologisch gebied verzameld in Nederlandsch Oost-Indië 1899-1900 XXIV 2 bis: 1-204.

Ewing RM. 1982. A partial revision of the genus Notomastus (Polychaeta: Capitellidae) with a description of a new species from the Gulf of Mexico. Proceedings of the Biological Society of Washington 95(2): 232-237.

Fauchald K. 1972. Benthic polychaetous annelids from deep waters off Western Mexico and adjacent areas in the Eastern Pacific Ocean. Allan Hancock Monographs in Marine Biology 7: 1-575.

Fauchald K. 1973. Polychaetes from central American sandy beaches. Bulletin of the Southern California Academy of Sciences 72: 19-31.

Fauchald K. 1977. The Polychaete Worms. Definitions and keys to the orders, families and genera. Natural History Museum of Los Angeles County, Science Series 28: 1-190.

García-Garza ME, de León-González JA. 2011. Review of the Capitellidae (Annelida, Polychaeta) from the Eastern Tropical Pacific region, with notes on selected species. Zookeys 151: 17-52. https://doi.org/10.3897/zookeys.151.1964

García-Garza ME, de León-González JA, Harris LH. 2017. Relocation of Dodecaseta McCammon \& Stull, 1978 (Annelida, Capitellidae) in Notodasus Fauchald, 1972. ZooKeys 715: 93-101. https://doi.org/10.3897/zookeys.715.13936

García-Garza ME, de León-González JA, and Tovar-Hernández. 2019. Catalogue of Notomastus M. Sars, 1851 (Annelida, Capitellidae) and the description of a new species from the Gulf of California. Zootaxa 4577(2): 249-273. https://doi.org/10.11646/zootaxa.4577.2.2

García-Garza ME, Hernández-Valdez VD, de León-González JA. 2009. Generic revision of Notodasus Fauchald, 1972 (Polychaeta: Capitellidae) with descriptions of four new species from the coasts of Mexico. Scientia Marina 73(4): 809-823. https://doi.org/10.3989/scimar.2009.73n- 4809

Green KD. 2002. Capitellidae (Polychaeta) from the Andaman Sea. In: Eibye Jacobsen D, ed. Proceedings of the international workshop on the Polychaetes of the Andaman Sea. Thailand: Phuket Marine Biological Center Special Publication, pp 249-343.

Grube AE. 1862. Noch ein Wort über die Capitellen und ihre Stelle im Systeme der Anneliden. Berlin: Archiv für Naturgeschichte, 378pp.

Hartmann-Schröder G. 1992. Die Polychaeten der Amsterdam-Expedition nach der Insel 
510

511

512

513

514

515

516

517

518

519

520

521

522

523

524

525

526

527

528

529

530

531

532

533

534

535

536

537

538

539

540

Ascension (Zentral-Atlantik). Bijdragen Tot De Dierkunde 61: 219-235.

Horst R. 1903. New species of the genus Euphrosyne from the Siboga Expedition with a table of the species hitherto known. Notes from the Leyden Museum 23: 213-222.

Horst R. 1910. On the genus Chloeia, with some new species from the Malay-Archipelago, partly collected by the Siboga Expedition. Notes from the Leyden Museum 32: 169-175.

Horst R. 1912. Polychaeta errantia of the Siboga Expedition. Part 1, Amphinomidae. SibogaExpeditie Uitkomsten op Zoologisch, Bonatisch, Oceanographisch en Geologisch gebied verzameld in Nederlandsch Oost-Indië 1899-1900 24a: 1-43, 10 plates. available online at https://biodiversitylibrary.org/page/2187401

Horst R. 1915. On new and little-known species of Polynoinae from the Netherlands' East-Indies. Zoologische Mededeelingen (Leiden) 1: 2-20.

Horst R. 1916a. On a new genus of Aphroditidae from the Netherlands East Indies. Zoologische Mededeelingen (Leiden) 2: 63-64.

Horst R. 1916b. Malayan species of the genera Aphroditella, Hermione, Laetmonice and Aphrogenia. Zoologische Mededeelingen (Leiden) 2(2): 65-77.

Horst R. 1917. Polychaeta Errantia of the Siboga Expedition. Part 2. Aphroditidae and Chrysopetalidae. Siboga-Expeditie Uitkomsten op Zoologisch, Bonatisch, Oceanographisch en Geologisch gebied verzameld in Nederlandsch Oost-Indië 1899-1900 24b: 1-140.

Horst R. 1924. Polychaeta errantia of the Siboga Expedition, Part 3. Nereidae and Hesionidae. Siboga-Expeditie Uitkomsten op Zoologisch, Bonatisch, Oceanographisch en Geologisch gebied verzameld in Nederlandsch Oost-Indië 1899-1900 24(1c): 145-198, pls 30-36.

Hutchings P. 2000. Family Capitellidae. In: Beesley PL, Ross GJB, Glasby CJ, eds. Polychaetes \& Allies: The Southern Synthesis. Fauna of Australia. Vol. 4A Polychaeta, Myzostomida, Pogonophora, Echiura, Sipuncula. Melbourne: CSIRO Publishing, pp 67-72.

Magalhães WF \& Bailey-Brock JH. 2012. Capitellidae Grube, 1862 (Annelida: Polychaeta) from the Hawaiian Islands with description of two new species. Zootaxa 3581: 1-52.

Magalhães WF \& Blake JA. 2017. Capitellidae Grube, 1862. In: Westheide W \& Purschke G, eds. Handbook of Zoology Online, a Natural History of the Phyla of the Animal KingdomAnnelida, Polychaetes. Boston: De Gruyter, Berlin. https://www.degruyter.com/view/Zoology/bp_029147-6_76.

Liu Ruiyu (ed). 2008. Checklist of marine biota of China seas. China Science Press, Beijing. (in 
541

542

543

544

545

546

547

548

549

550

551

552

553

554

555

556

557

558

559

560

561

562

563

564

565

566

567

568

569

570

571

Chinese)

McCammon JA, Stull JK. 1978. A new genus and species of Capitellidae (Polychaeta) from California. Bulletin of the Southern California Academy of Sciences 77(1): 40-43.

Pamungkas J. 2015. The description of a new species Polymastigos javaensis n. sp. (Annelida: Capitellidae) from the Segara Anakan mangroves, Central Java, Indonesia. Zootaxa 3980(2): 279-285. https://doi.org/10.11646/zootaxa.3980.2.8.

Pamungkas J. 2017. Capitella ambonensis: a new polychaete species (Annelida: Capitellidae) collected from a mangrove habitat on Ambon Island, Indonesia. Zootaxa 4227(4): 573-582.

Pamungkas J, Glasby CJ, Read GB, Wilson SP, Costello MJ. 2019. Progress and perspectives in the discovery of polychaete worms (Annelida) of the world. Helgoland Marine Research 73: 4. https:// doi.org/10.1186/s10152-019-0524-z

Pearson TH \& Rosenberg R. 1978. Macrobenthic succession in relation to organic enrichment and pollution of the marine environment. Oceanography and Marine Biology, Annual Review 16: 229-311.

Pettibone MH. 1970. Polychaeta errantia of the Siboga Expedition. Part IV. Some additional polychaetes of the Polynoidae, Hesionidae, Nereidae, Goniadidae, Eunicidae and Onuphidae, selected as new species by the late Dr. Hermann Augener, with remarks on other related species. In: Weber M, Beaufort LF, Stock JH, eds. Siboga-Expeditie Uitkomsten op Zoologisch, Bonatisch, Oceanographisch en Geologisch gebied verzameld in Nederlandsch Oost-Indië 1899-1900. Leiden, E.J. Brill, 199-270.

Pettibone MH. 1971. Partial revision of the genus Sthenelais Kinberg (Polychaeta: Sigalionidae) with diagnoses of two new genera. Smithsonian Contributions to Zoology 109: 1-40. available online at http://si-pddr.si.edu/dspace/handle/10088/5688

Read G \& Fauchald K. (Ed.) 2018. World Polychaeta database. Capitellidae Grube, 1862. Accessed at: http://marinespecies.org/polychaeta/aphia.php?p=taxdetails\&id=921 (accessed 31 December 2018)

Reish DJ. 1980. The effect of different pollutants on ecologically important polychaete worms. U.S.E.P.A. Report, EPA-600/3-80-053. 138pp.

Warren LM. 1991. Problems in capitellid taxonomy. The genera Capitella, Capitomastus and Capitellides (Polychaeta). Ophelia 5: 275-282.

Warren LM, Hutchings PA, Doyle S. 1994. A revision of the genus Mediomastus Hartman, 1944 
572 (Polychaeta: Capitellidae). Records of the Australian Museum 46(3): 227-256.

$573 \quad$ https://doi.org/10.3853/j. 0067-1975.46.1994.6 
Figure 1

Type localities of described species of Notodasus worldwide

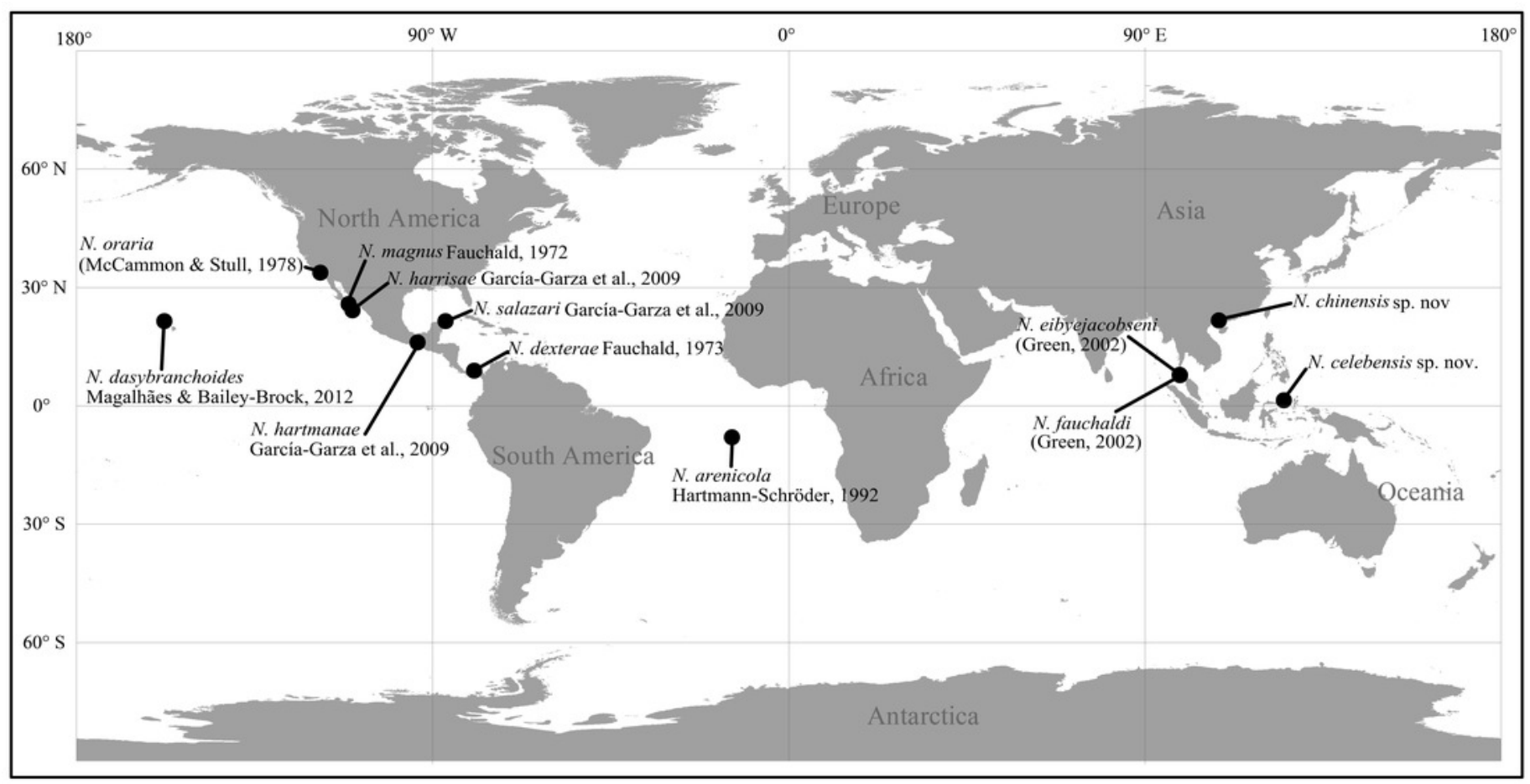


Figure 2

Map of survey areas

(A) sampling stations in the Qinzhou Bay, the southern coast of China, and (B) sampling stations in mixed-species seagrass beds of northern Sulawesi Island, Indonesia 


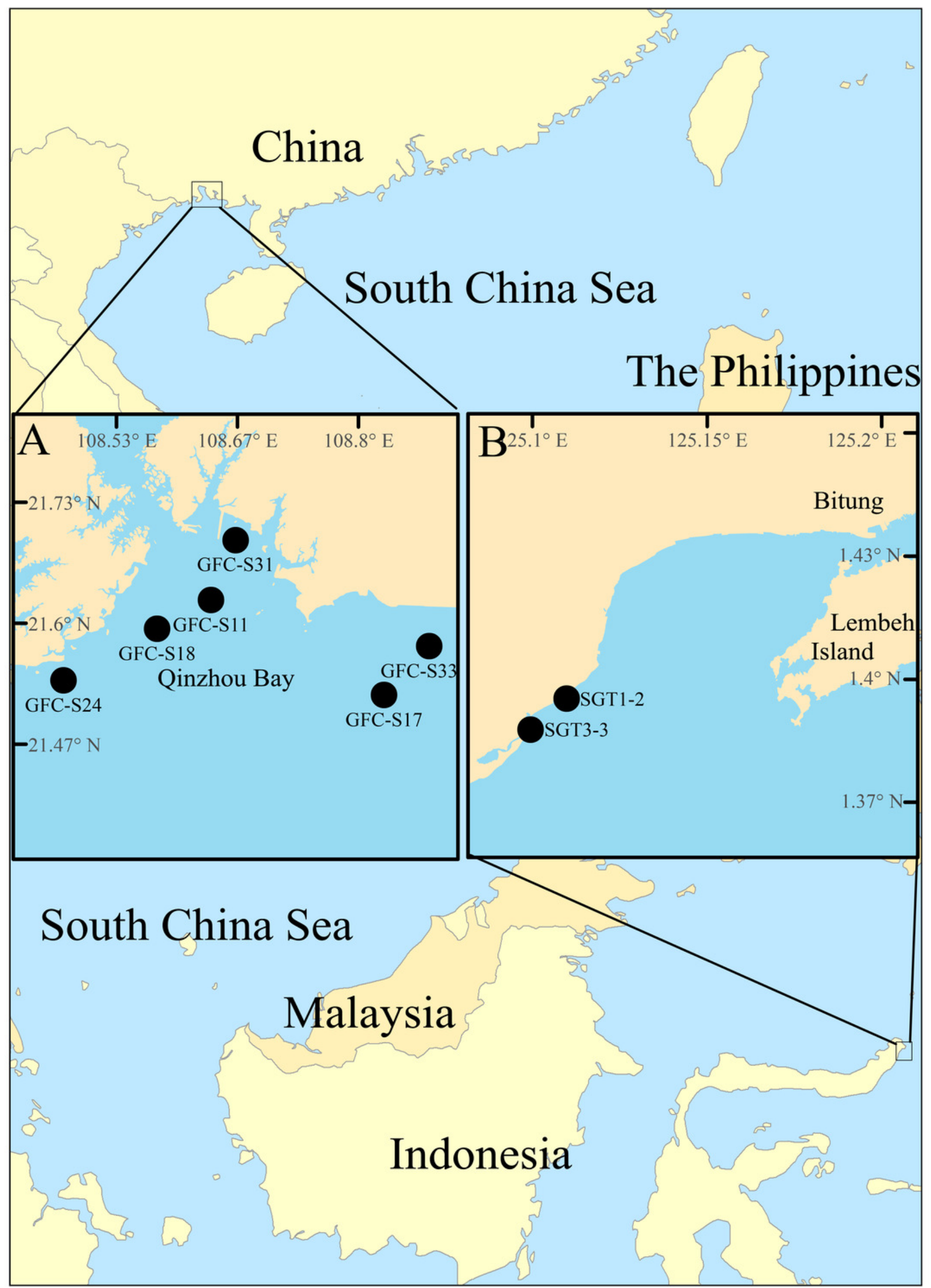




\section{Figure 3}

Photomicrographs of Notodasus celebensis sp. nov.

(A) Thorax and anterior abdomen, lateral view, arrow indicating the separation between thorax and abdomen. (B) Anterior end, lateral view. (C) Prostomium with digitate palpode, lateral view. (D) Longitudinally striated epithelium, lateral view. (E) Transition between thorax and abdomen, lateral view. (F) Anterior abdomen, dorsal view. (G) Posterior part, lateral view. Abbreviations: cc: capillary chaetae; ch: chaetiger; hh: hooded hook; lo: lateral organ; neu: neuropodium; no: notopodium;pal: palpode; per: perstomium. (Photoes by Junhui Lin) 

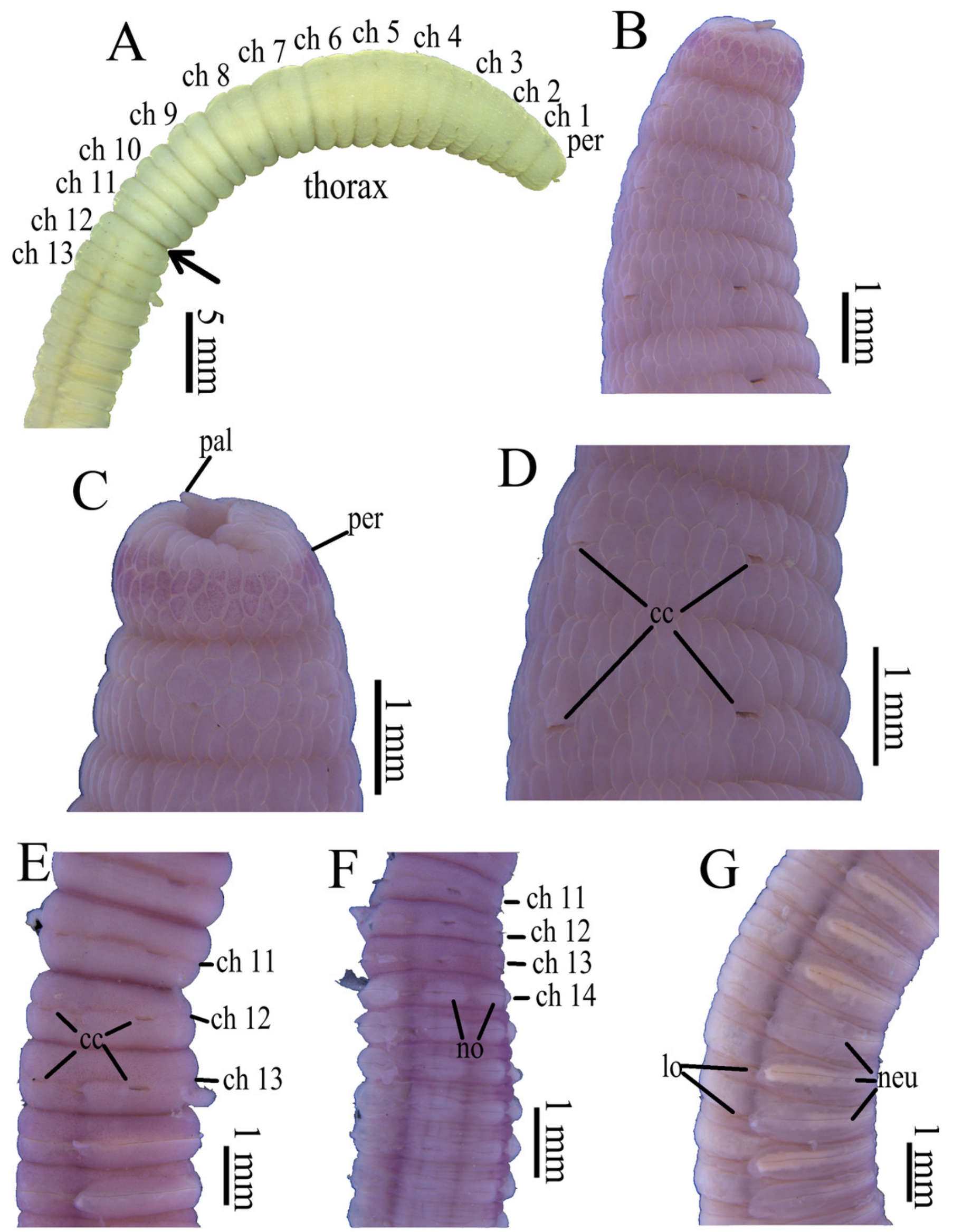


\section{Figure 4}

Holotype of Notodasus celebensis sp. nov. (TIO-BTS-Poly 101)

(A) Anterior 17 chaetigers, lateral view. (B) Anterior end, lateral view. (C) Chaetigers 10-20, dorsal view, showing transition between thorax and abdomen. (D) Chaetigers 10-16, lateral view. (E) Chaetigers 12-18, ventrolateral view. (F) Chaetigers 32-40, lateral view. (G) Neuropodial hook from chaetiger 40 . Shading on A-E indicates methyl green staining. Scale bars: A-F, $1 \mathrm{~mm} ; \mathrm{G}, 20 \mu \mathrm{m}$. (Drawing by Junhui Lin) 

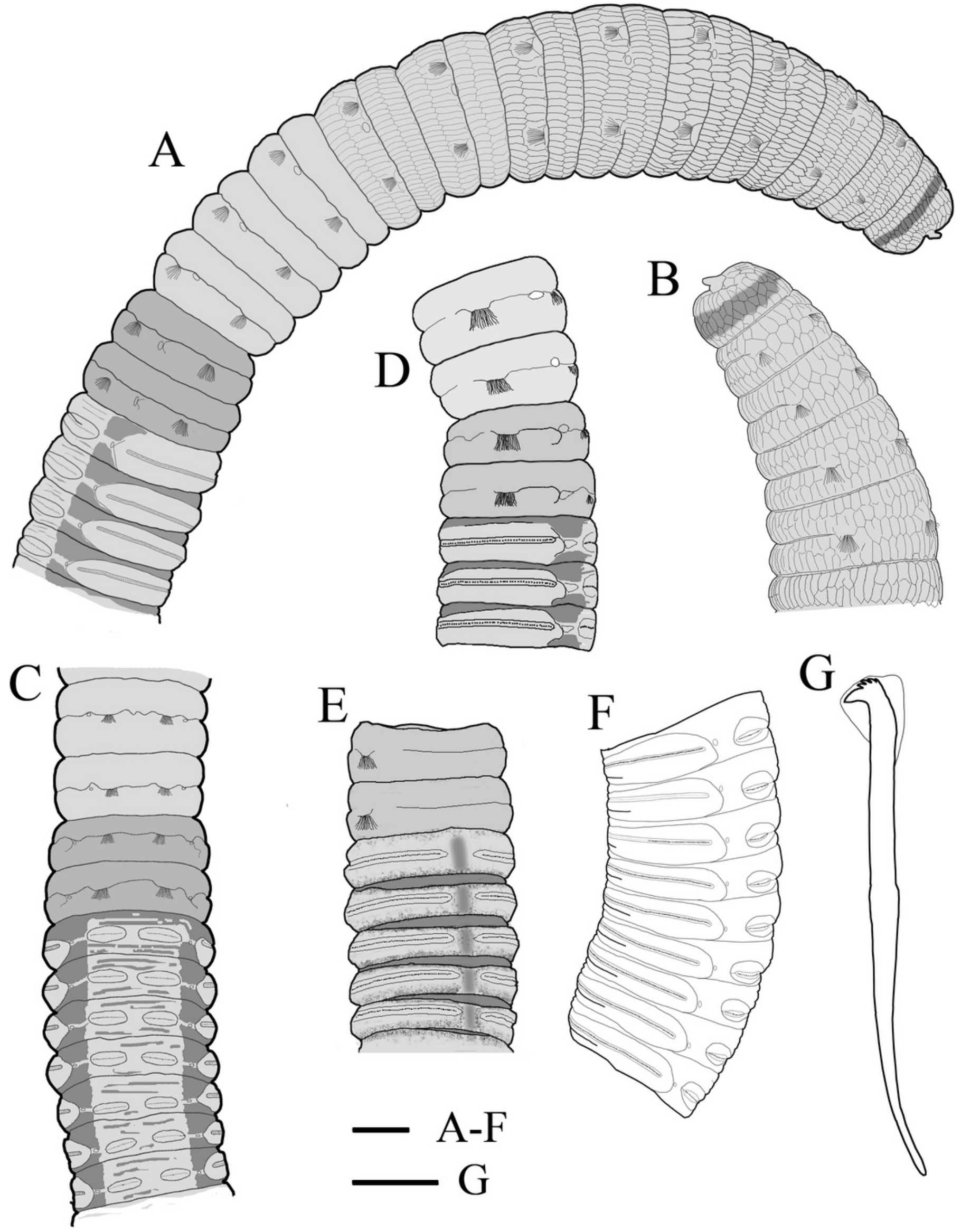

$\mathrm{G}$

Peer) reviewing PDF | (2019:04:36363:1:1:NEW 31 Jul 2019) 


\section{Figure 5}

Notodasus species with longitudinally striated epithelium

Holotype of N. magnus: (A) Anterior end, lateral view. (B) Chaetigers 12-17, dorsal view.

Holotype of N. harrisae: (C) Anterior end, lateral view. (D) Chaetigers 11-22, dorsal view.

Paratype of N. fauchaldi: (E) Anterior end, dorsal view. (F) Chaetigers 11-17, dorsal view.

Holotype of N. celebensis sp. nov., (G) Anterior end, lateral view. (H) Chaetigers 10-19, dorsal

view. Methyl green stain: B-H. Scale bars: A-H, 1 mm. (Photoes A-F by María E. García-Garza;

Photoes G-H by Junhui Lin) 

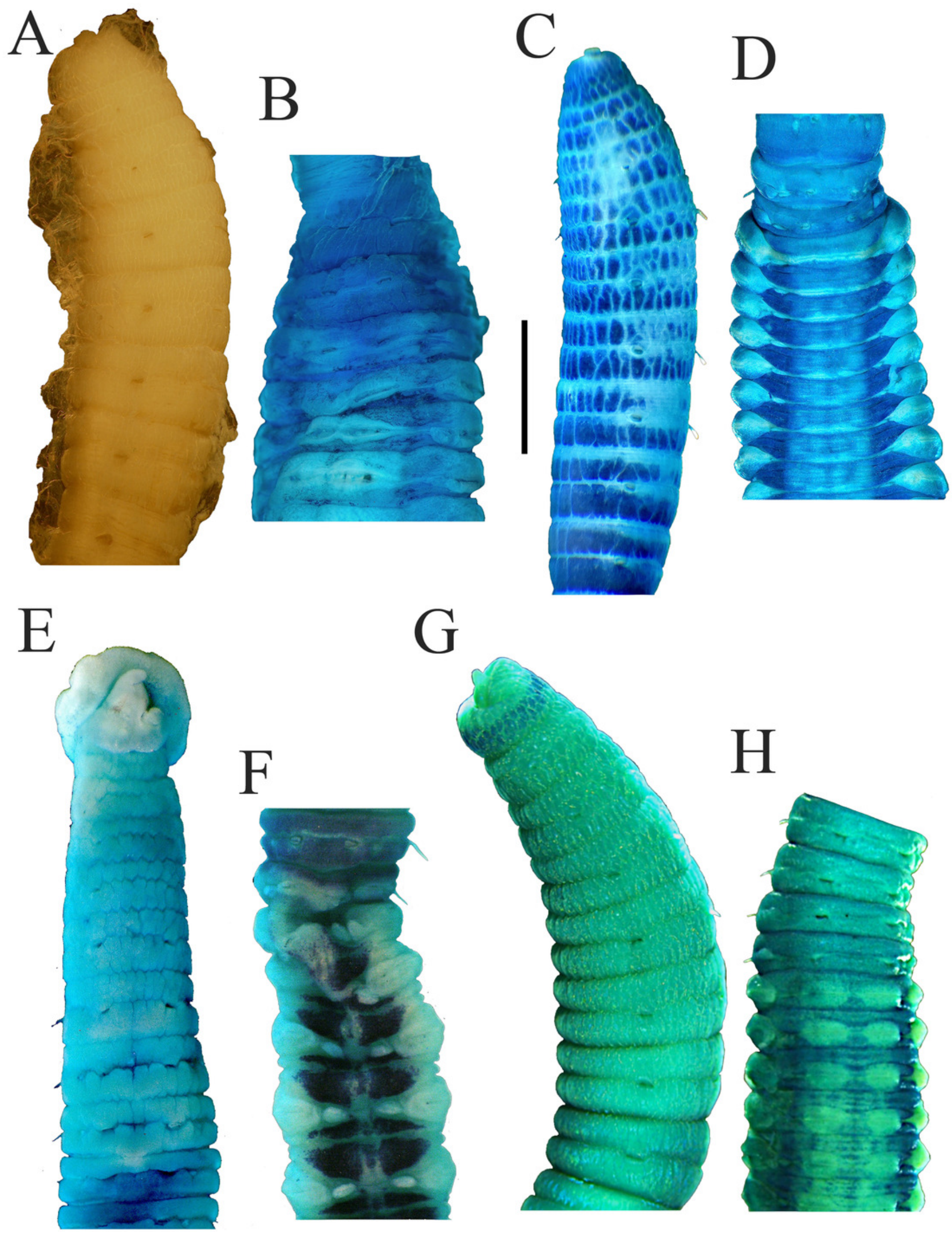

Peer) reviewing PDF | (2019:04:36363:1:1:NEW 31 Jul 2019) 


\section{Figure 6}

Photomicrographs of Notodasus chinensis sp. nov.

(A) Thorax and anterior abdomen, lateral view. (B) Anterior thorax, dorsolateral view. (C) Transition between thorax and abdomen, dorsolateral view. (D) Transition between thorax and abdomen, lateral view. (E) Anterior abdomen, showing branchial pores, lateral view. (F) Posterior part of holotype, showing retractile branchiae and lateral organs, lateral view. Abbreviations: bp: branchial pore; br: branchia; cc: capillary chaetae; ch: chaetiger; hh: hooded hook; lo: lateral organ; neu: neuropodium. (Photoes by Junhui Lin) 


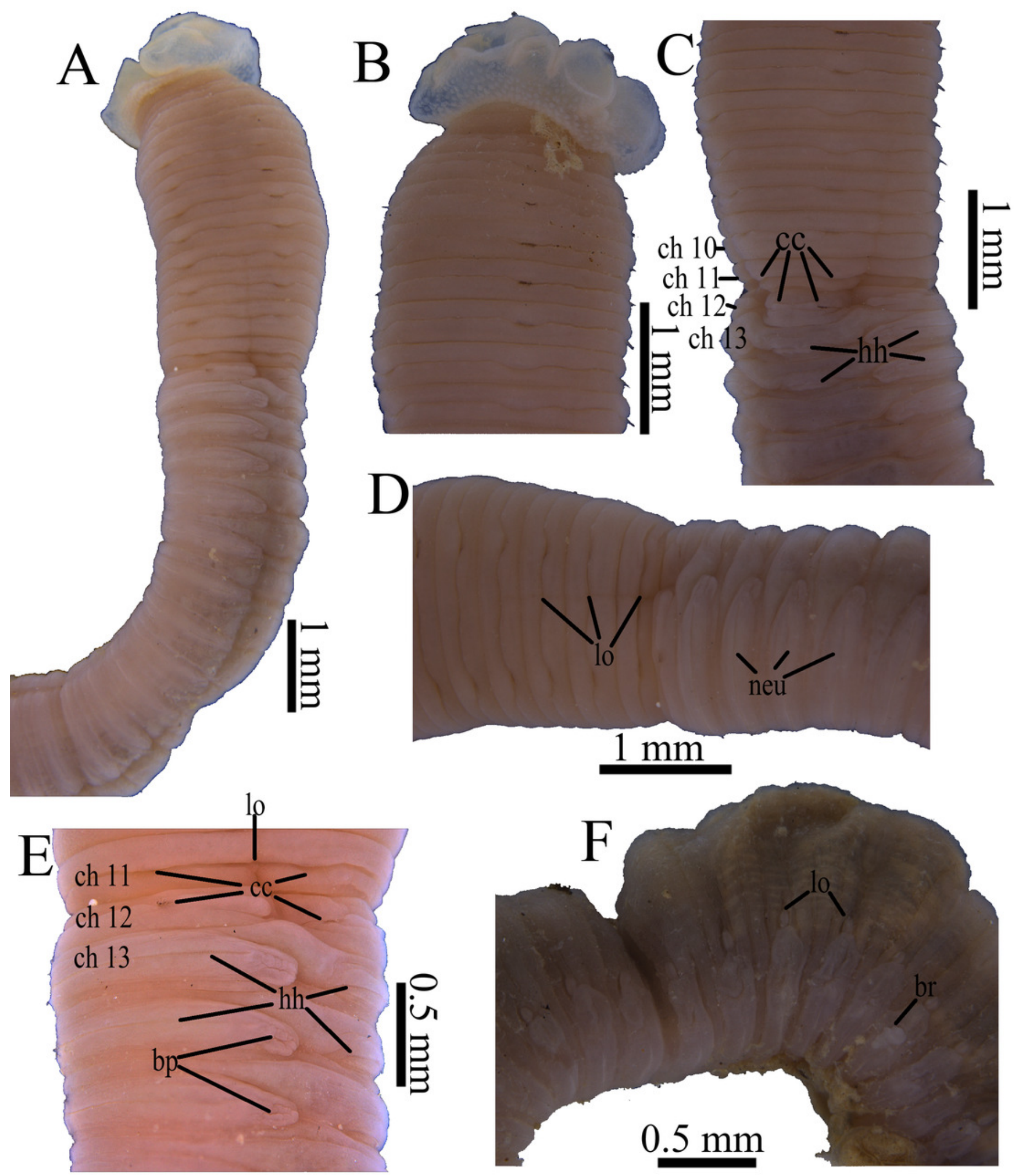




\section{Figure 7}

Scanning electron micrographs of Notodasus chinensis sp. nov. (TIO-BTS-Poly-106)

(A) Anterior end, dorsolateral view. (B) Transition between thorax and abdomen, dorsolateral view. (C) Capillary chaetae from chaetiger 9. (D) Abdominal hooded hooks. Abbreviations: cc: capillary chaetae; ch: chaetiger; hh: hooded hook; lo: lateral organ. (Photoes by Junhui Lin) 

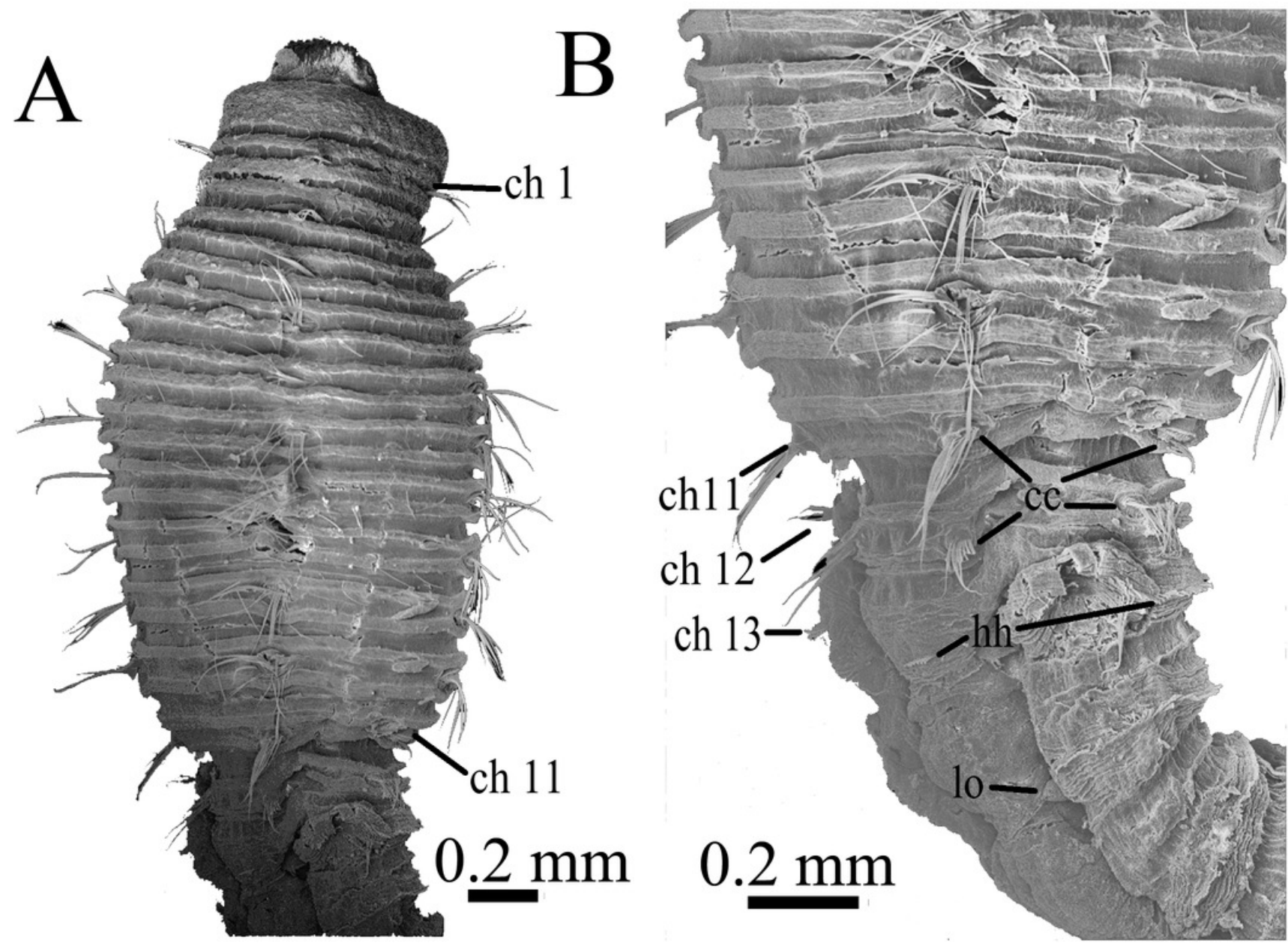

$0.2 \mathrm{~mm}$

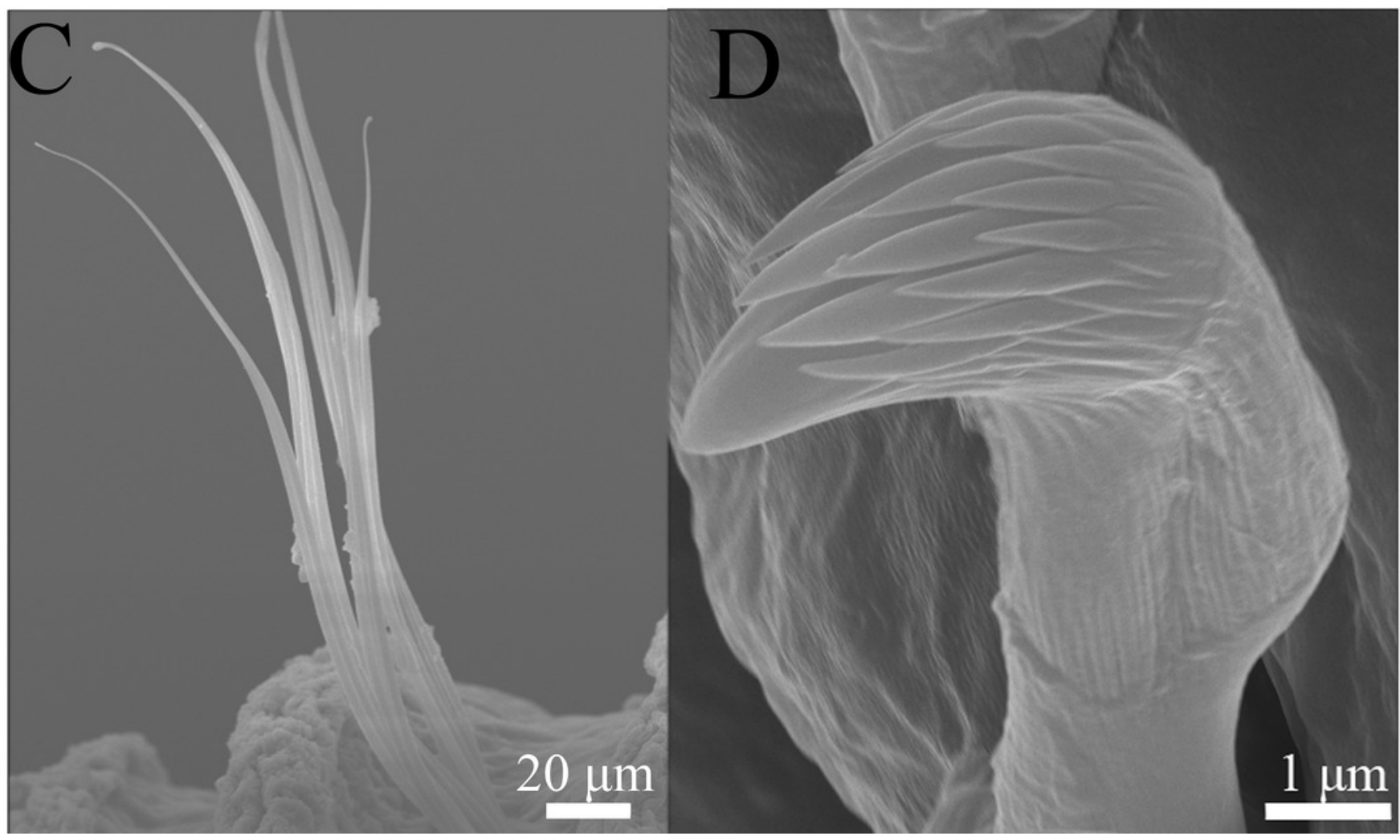


Figure 8

Holotype of Notodasus chinensis sp. nov.

(A) Anterior 17 chaetigers, dorsolateral view. (B) Anterior end, lateral view. (C) Chaetigers 11-18, dorsolateral view, showing transition between thorax and abdomen. (D) Chaetigers 10-20, ventral view. (E) Chaetigers 55-67, lateral view. (F) Neuropodial hook from chaetiger 40. Shading on A-C indicates methyl green staining. Scale bar: $A-E=1 \mathrm{~mm} ; F=10 \mu \mathrm{m}$. (Drawing by Junhui Lin) 

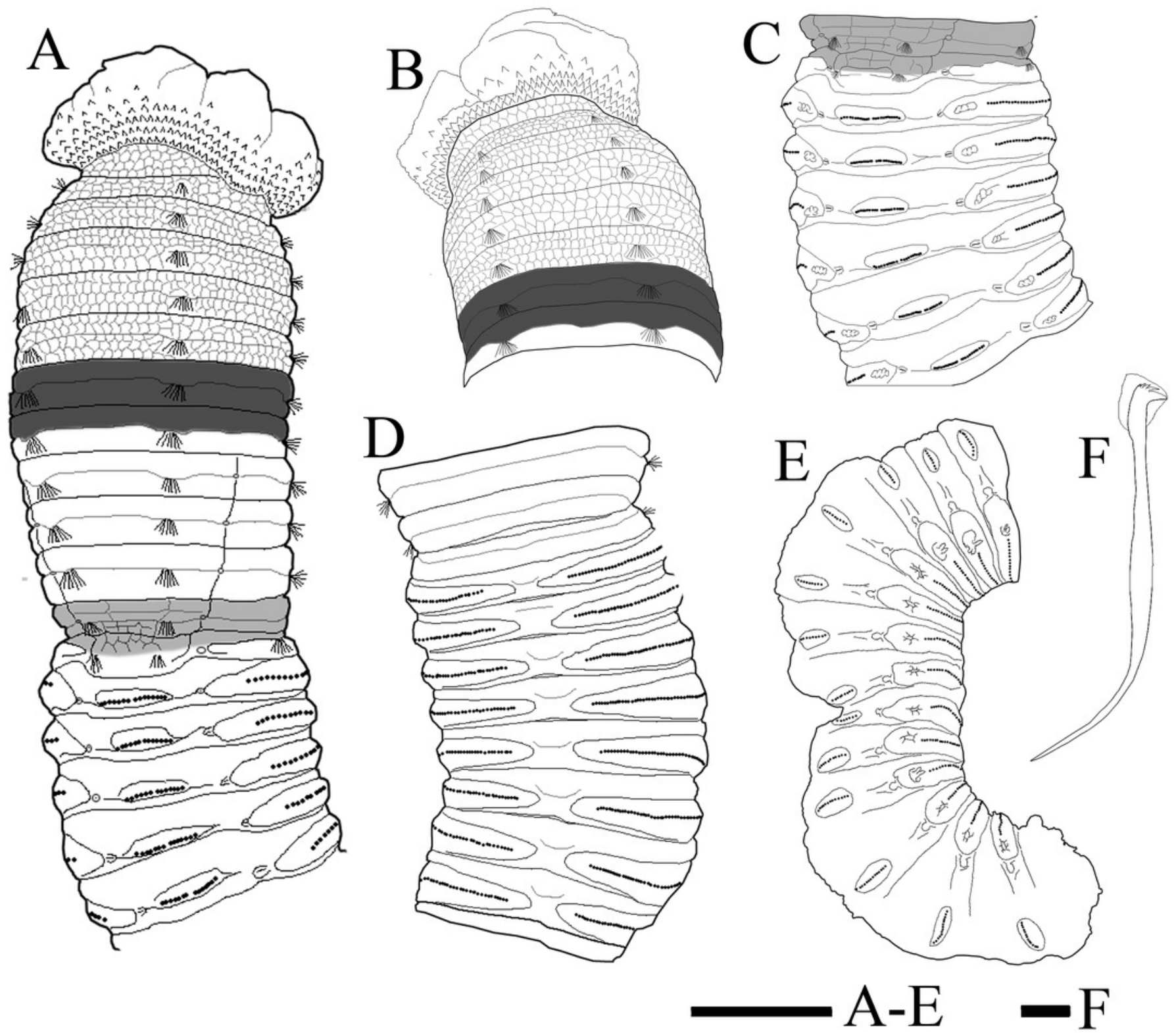


\section{Figure 9}

Methyl green staining patterns

(A-B) Notodasus chinensis sp. nov. (A) Anterior end, dorsolateral view (TIO-BTS-Poly-106). (B) Anterior end, dorsal view (TIO-BTS-Poly-110). (C) N. oraria holotype, anterior end, dorsolateral view. (D-E) N. dexterae holotype. (D) Anterior end, lateral view. (E) Chaetigers 11-17, dorsal view. (Photoes A-B by Junhui Lin; Photoes C-E by María E. García-Garza)
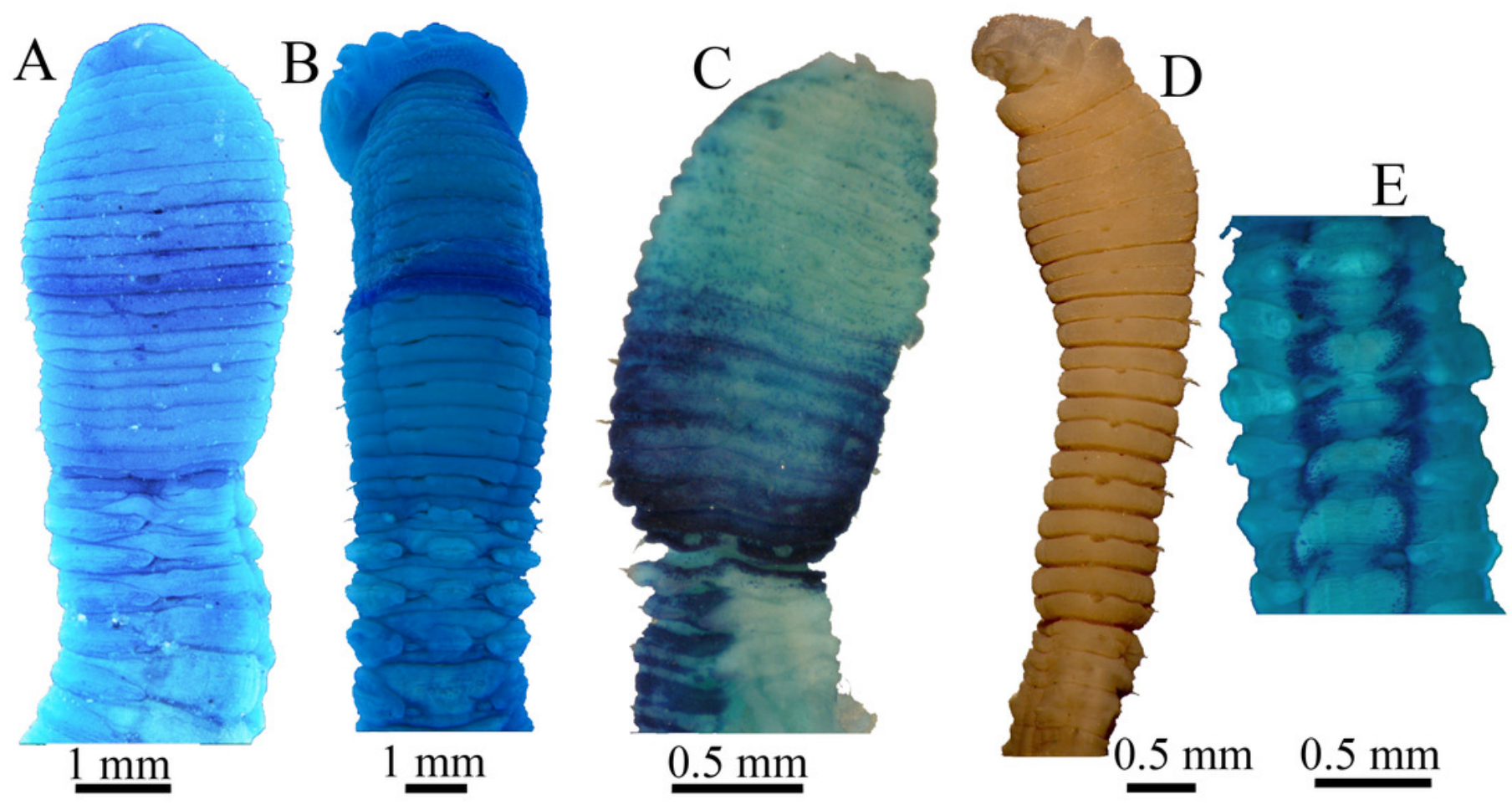


\section{Table 1 (on next page)}

Sampling stations where Notodasus specimens were collected 
1

2 Table 1 Sampling stations where Notodasus specimens were collected

\begin{tabular}{|c|c|c|c|c|c|c|c|}
\hline \multirow[b]{2}{*}{ Locality } & \multirow[b]{2}{*}{ Station } & \multirow{2}{*}{$\begin{array}{l}\text { Specimen } \\
\text { amount }\end{array}$} & \multirow{2}{*}{$\begin{array}{c}\text { Date } \\
\text { (dd/mm/yyyy) }\end{array}$} & \multirow[b]{2}{*}{ Longitude } & \multicolumn{3}{|c|}{ Depth } \\
\hline & & & & & Latitude & (m) & Substrate \\
\hline Sulawesi Island & SGT 1-2 & 1 & $23 / 05 / 2014$ & $125^{\circ} 06^{\prime} 43^{\prime \prime} \mathrm{E}$ & $1^{\circ} 23^{\prime} 41^{\prime \prime} \mathrm{N}$ & 1 & Fine sand \\
\hline (Indonesia) & SGT 3-3 & 2 & $25 / 05 / 2014$ & $125^{\circ} 06^{\prime} 08^{\prime \prime} \mathrm{E}$ & $1^{\circ} 23^{\prime} 11^{\prime \prime} \mathrm{N}$ & 1 & Fine sand \\
\hline Guangxi Province & GFC-S11 & 1 & $27 / 10 / 2017$ & $108^{\circ} 38^{\prime} 15^{\prime \prime} \mathrm{E}$ & $21^{\circ} 37^{\prime} 33^{\prime \prime} \mathrm{N}$ & 12 & Mud \\
\hline \multirow[t]{5}{*}{ (China) } & GFC-S24 & 2 & $27 / 10 / 2017$ & $108^{\circ} 28^{\prime} 29^{\prime \prime} \mathrm{E}$ & $21^{\circ} 32^{\prime} 14^{\prime \prime} \mathrm{N}$ & 11 & Mud \\
\hline & GFC-S31 & 5 & $26 / 01 / 2018$ & $108^{\circ} 39^{\prime} 52^{\prime \prime} \mathrm{E}$ & $21^{\circ} 41^{\prime} 31^{\prime \prime} \mathrm{N}$ & 8 & Mud \\
\hline & GFC-S33 & 1 & $26 / 01 / 2018$ & $108^{\circ} 52^{\prime} 41^{\prime \prime} \mathrm{E}$ & $21^{\circ} 34^{\prime} 30^{\prime \prime} \mathrm{N}$ & 7 & Muddy sand \\
\hline & GFC-S17 & 2 & $21 / 04 / 2018$ & $108^{\circ} 49^{\prime} 42^{\prime \prime} \mathrm{E}$ & $21^{\circ} 31^{\prime} 16^{\prime \prime} \mathrm{N}$ & 7 & Mud \\
\hline & GFC-S18 & 1 & $22 / 04 / 2018$ & $108^{\circ} 34^{\prime} 41^{\prime \prime} \mathrm{E}$ & $21^{\circ} 35^{\prime} 39^{\prime \prime} \mathrm{N}$ & 9 & Muddy sand \\
\hline
\end{tabular}

3 
Table 2 (on next page)

Comparisons of closely related species in the genus 


\section{Table 2 Comparisons of closely related species in the genus}

\begin{tabular}{|c|c|c|c|c|}
\hline $\begin{array}{l}\text { Morphological } \\
\text { characters }\end{array}$ & $\begin{array}{l}\text { N. celebensis sp. nov. } \\
\text { Holotype }\end{array}$ & $\begin{array}{l}\text { N. fauchaldi } \\
\text { (Green, 2002) } \\
\text { Paratype }\end{array}$ & $\begin{array}{l}\text { N. harrisae } \\
\text { García-Garza et al., } 2009 \\
\text { Holotype }\end{array}$ & $\begin{array}{l}\text { N. magnus } \\
\text { Fauchald, } 1972 \\
\text { Holotype }\end{array}$ \\
\hline $\begin{array}{l}\text { Body width in } \\
\text { abdomen }\end{array}$ & $2.8 \mathrm{~mm}$ & $0.7 \mathrm{~mm}$ & $2 \mathrm{~mm}$ & $5 \mathrm{~mm}$ \\
\hline Eyespots & Absent & Present & Present & Absent \\
\hline Prostomium & Rounded with palpode & Conical with palpode & Conical with palpode & Conical with palpode \\
\hline Thoracic epithelium & $\begin{array}{l}\text { Longitudinally striated } \\
\text { through chaetiger } 8\end{array}$ & $\begin{array}{l}\text { Longitudinally striated } \\
\text { through chaetiger } 7\end{array}$ & $\begin{array}{l}\text { Longitudinally striated } \\
\text { through chaetiger } 11\end{array}$ & $\begin{array}{l}\text { Longitudinally striated } \\
\text { except for peristomium }\end{array}$ \\
\hline $\begin{array}{l}\text { Degree of fused } \\
\text { notopodia in anterior } \\
\text { abdomen }\end{array}$ & Completely free & $\begin{array}{l}\text { Notopodia fused dorsally } \\
\text { but chaetal fascicles } \\
\text { separated }\end{array}$ & $\begin{array}{l}\text { Notopodia fused dorsally } \\
\text { and chaetal fascicles almost } \\
\text { fused }\end{array}$ & $\begin{array}{l}\text { Notopodia fused dorsally } \\
\text { with a median } \\
\text { constriction, and chaetal } \\
\text { fascicles fused }\end{array}$ \\
\hline $\begin{array}{l}\text { Dental structure of } \\
\text { hooded hooks }\end{array}$ & $\begin{array}{l}\text { Four rows of small } \\
\text { teeth above main fang }\end{array}$ & $\begin{array}{l}\text { Four rows of small teeth } \\
\text { above main fang }\end{array}$ & $\begin{array}{l}\text { Three rows of small teeth } \\
\text { above main fang }\end{array}$ & $\begin{array}{l}\text { Three rows of small teeth } \\
\text { above main fang }\end{array}$ \\
\hline $\begin{array}{l}\text { Shape of the shaft of } \\
\text { hooded hooks }\end{array}$ & With angled node & With bulbous node & With angled node & With angled node \\
\hline $\begin{array}{l}\text { Abdominal lateral } \\
\text { organs }\end{array}$ & $\begin{array}{l}\text { As a small } \\
\text { protuberance in the pits }\end{array}$ & Protruded above surface & $\begin{array}{l}\text { As a small protuberance in } \\
\text { the pits }\end{array}$ & Protruded above surface \\
\hline Pygidium & Unknown & Unknown & Unknown & Unknown \\
\hline Branchiae & Unknown & Unknown & $\begin{array}{l}\text { Evident from chaetiger } 60 \text {, } \\
\text { with around } 14 \text { filaments }\end{array}$ & $\begin{array}{l}\text { Evident from chaetiger } \\
61, \text { with around } 6 \\
\text { filaments }\end{array}$ \\
\hline Habitat & $1 \mathrm{~m}$; fine sand & $\begin{array}{l}21-55 \mathrm{~m} \text {; sandy mud, } \\
\text { muddy sand, and sand } \\
\text { with shell fragments }\end{array}$ & $0-1 \mathrm{~m}$; fine or coarse sand & $\begin{array}{l}29-35 \mathrm{~m} \text {; mixed sediment } \\
\text { of sand, mud, and pebbles }\end{array}$ \\
\hline Type locality & $\begin{array}{l}\text { Sulawesi Island, } \\
\text { Indonesia }\end{array}$ & Andaman Sea, Thailand & Gulf of California & Gulf of California \\
\hline Reference & This study & García-Garza et al., 2017 & García-Garza et al., 2009 & García-Garza et al., 2009 \\
\hline
\end{tabular}


Table 3 (on next page)

Comparisons of closely related species in the genus 
1

2 Table 3 Comparisons of closely related species in the genus

\begin{tabular}{|c|c|c|c|}
\hline $\begin{array}{l}\text { Morphological } \\
\text { characters }\end{array}$ & $\begin{array}{l}\text { N. chinensis sp. nov. } \\
\text { Holotype }\end{array}$ & $\begin{array}{l}\text { N. oraria } \\
\text { (McCammon \& Stull, 1978) } \\
\text { Holotype }\end{array}$ & $\begin{array}{l}\text { N. dexterae } \\
\text { García-Garza et al., } 2009 \\
\text { Holotype }\end{array}$ \\
\hline Body width in abdomen & $1.7 \mathrm{~mm}$ & $0.8 \mathrm{~mm}$ & $1 \mathrm{~mm}$ \\
\hline Eyespots & Present & Absent & Present \\
\hline Prostomium & Conical with short palpode & Conical with palpode & Conical with distal palpode \\
\hline Thoracic epithelium & $\begin{array}{l}\text { Tessellated through chaetiger } \\
5\end{array}$ & $\begin{array}{l}\text { Tessellated through chaetiger } \\
8\end{array}$ & $\begin{array}{l}\text { tessellated through chaetiger } \\
5\end{array}$ \\
\hline $\begin{array}{l}\text { Degree of fused } \\
\text { notopodia in anterior } \\
\text { abdomen }\end{array}$ & $\begin{array}{l}\text { Notopodial lobes fused and } \\
\text { Chaetal fascicles almost } \\
\text { touching }\end{array}$ & $\begin{array}{l}\text { Notopodial lobes fused } \\
\text { dorsally but chaetal fascicles } \\
\text { separated }\end{array}$ & $\begin{array}{l}\text { Notopodial lobes fused } \\
\text { dorsally but chaetal fascicles } \\
\text { separated }\end{array}$ \\
\hline $\begin{array}{l}\text { Dental structure of } \\
\text { hooded hooks }\end{array}$ & $\begin{array}{l}\text { Four rows of small teeth } \\
\text { above main fang }\end{array}$ & $\begin{array}{l}\text { Four rows of small teeth } \\
\text { above main fang }\end{array}$ & $\begin{array}{l}\text { Five rows of small teeth } \\
\text { above main fang }\end{array}$ \\
\hline $\begin{array}{l}\text { Shape of the shaft of } \\
\text { hooded hooks }\end{array}$ & With bulbous node & With bulbous node & With bulbous node \\
\hline Lateral organs & $\begin{array}{l}\text { As a small protuberance in the } \\
\text { pits but protruded above } \\
\text { surface in posterior segments }\end{array}$ & Protruded & Protruded above surface \\
\hline Pygidium & Unknown & Unknown & Unknown \\
\hline Branchiae & Present, retractile & Present & Unknown \\
\hline Habitat & $7-12 \mathrm{~m}$; mud or muddy sand & $1-180 \mathrm{~m} ; \mathrm{mud}$ & intertidal sand \\
\hline Type locality & Guangxi Province, China & Waters off California, USA & $\begin{array}{l}\text { Naos Island, Pacific coast of } \\
\text { Panama }\end{array}$ \\
\hline Reference & This study & García-Garza et al., 2017 & García-Garza et al., 2009 \\
\hline
\end{tabular}

